WORKING PAPER · NO. 2020-21

\title{
Launching with a Parachute: The Gig Economy and Entrepreneurial Entry
}

John M. Barrios, Yael V. Hochberg, and Hanyi Yi MARCH 2020

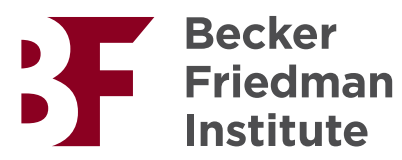




\title{
LAUNCHING WITH A PARACHUTE: THE GIG ECONOMY AND ENTREPRENEURIAL ENTRY*
}

\author{
John M. Barrios \\ University of Chicago Booth School of Business \\ Yael V. Hochberg \\ Rice University \& NBER \\ Hanyi Yi \\ Rice University
}

First Version: January 10, 2020

Current Version: March 16, 2020

\begin{abstract}
The introduction of the gig economy creates opportunities for would-be entrepreneurs to supplement their income in downside states of the world, and provides insurance in the form of an income fallback in the event of failure. We present a conceptual framework supporting the notion that the gig economy may serve as an income supplement and as insurance against entrepreneurial-related income volatility, and utilize the arrival of the on-demand, platform-enabled gig economy in the form of the staggered rollout of ridehailing in U.S. cities to examine the effect of the arrival of the gig economy on entrepreneurial entry. The introduction of gig opportunities is associated with an increase of $\sim 5 \%$ in the number of new business registrations in the local area, and a correspondingly-sized increase in small business lending to newly registered businesses. Internet searches for entrepreneurship-related keywords increase $\sim 7 \%$, lending further credence to the predictions of our conceptual framework. Both the income supplement and insurance channels are empirically supported: the increase in entry is larger in regions with lower average income and higher credit constraints, as well as in locations with higher ex ante economic uncertainty regarding future wage levels and wage growth.
\end{abstract}

JEL Codes: L26, G39, O3

\footnotetext{
* We thank Rustam Abuzov, Jonathan Bonham, Florian Ederer, Alex Frankel, Song Ma, Gustav Martinsson, David Robinson, Joachim Tag, and workshop participants at Yale University and the KWC Conference on Entrepreneurial Finance for helpful conversations, comments and suggestions. Esther Bailey and Yupeng Liu provided excellent research assistance. We are grateful to the Startup Cartography Project and Jorge Guzman for provision of data used in this project. All errors are our own. Barrios gratefully acknowledges the support of the Stigler Center and the Centel Foundation/Robert P. Reuss Fund at the University of Chicago Booth School of Business. Corresponding Author: Yael Hochberg (hochberg@,rice.edu), Rice University, 6100 Main St. MS-531, Houston, TX 77005.
} 


\section{INTRODUCTION}

As far back as Knight (1921), scholars have argued that bearing risk is one of the essential characteristics of entrepreneurship. Because the capital markets provide too little capital to entrepreneurs as a result of moral hazard and adverse selection problems (e.g., LeRoy and Singell 1987), entrepreneurs must finance themselves and bear the risk of failure. Empirical research on the relationships between wealth constraints and entrepreneurship (Jensen et al. 2014), job protection and entrepreneurial activity (Gottlieb et al. 2018), and unemployment insurance and new business formation (Hombert et al. 2020) in countries outside the U.S. are consistent with this view. Under a Knightian perspective, the relaxation of the personal liquidity constraint through provision of a channel for income supplement and/or through provision of employment fallbacks that serve as insurance for failed entrepreneurs should encourage additional entrepreneurial entry. In this paper, we argue that the arrival of the platform-enabled, on-demand gig economy, with its flexible work hours and low entry barriers, provides just such a supplement to entrepreneurial income as well as insurance against entrepreneurial-related income volatility, and empirically explore the effect of its arrival on the emergence of new entrepreneurial ventures.

We focus on incorporated business starts, as the factors that drive entry into entrepreneurship likely differ across the various types of entrepreneurship. While the income opportunities option provided by the gig economy may entice risk-bearing would-be entrepreneurs to launch new companies, at the same time, for individuals engaged in ad hoc self-employment, the gig economy offers the potential for a steadier "employment"-like opportunity. Though technically every gig economy worker is, in fact, self-employed, many of these individuals self-classify as "working for Uber (Lyft)" and do not report themselves as self-employed in self-reported survey measures. Burtch et al. (2018) utilize this fact to show that with the entry of the gig economy, self-reported self-employment from the Current Population Survey-primarily unincorporated selfemployment - goes down, consistent with the notion of some self-employed workers transitioning to working in the gig economy (and consequently classifying themselves as "working for Uber (or Lyft)" rather than being self-employed). The effect of the availability of gig economy opportunities on new (incorporated) business launches - which differ considerably from low-quality selfemployment, which is the source of the impacts in Burtch et al. (2018)-remains, however, unexplored.

We begin by presenting a conceptual framework to illustrate the likely effects of the arrival of

the on-demand platform-driven gig economy on (pecuniary) new business launch, motivated by 
the Knight (1921) view that an individual's decision to enter entrepreneurship versus full-time wage-employment is determined by the relative returns offered by the two choices. The framework, which models new business launches as a function of the difference in average wages earned under entry versus full-time employment as well as the volatility of entrepreneurial income in the local region, suggests an income supplement effect and an insurance effect that both serve to increase entrepreneurial entry when gig economy earning opportunities exist.

We then turn to examining these predictions empirically. To do this, we utilize a relatively novel dataset of actual new business registrations in a local region, provided by the Startup Cartography Project (SCP) (http://www.startupcartography.com). Because a new company must not only incorporate in a state jurisdiction (which may not be the state they operate in), but also register their to do business with their local Secretary of State (where the business actually operates), and because such registrations provide an actual operating address for the new company, utilizing business registration data allows us to observe the full universe of newly incorporated businesses. The SCP dataset provides us with counts, by zip-code and quarter, of all new for-profit businesses, allowing us to observe entrepreneurial entry at the micro level. Utilizing incorporated business registrations rather than measures of "self-employment" both allows us to capture the type of entrepreneurial entry we are most interested in (businesses who have taken a form required for possible growth) as well as avoid the concern that any increase in measures of "selfemployment" may simply be capturing gig economy workers, who by definition are contractors and therefore self-employed. Since individual drivers on ridehailing platforms in the U.S. rarely, if ever, incorporate, ${ }^{1}$ newly registered incorporated businesses should also not be related to driving for ridehailing companies as an individual.

We utilize the arrival of ridehailing platforms as a proxy for the launch of the gig economy writ large. ${ }^{2}$ Ridehailing platforms such as Uber and Lyft allow drivers, once approved, to use their own or rented cars to offer rides whenever they choose. There are no minimum hour requirements and only modest constraints on maximum hours. Thus, drivers can work whenever they want to. Moreover, the arrival of these platforms often heralds the arrival of other gig economy platforms such as food delivery, errand running, or package delivery.

\footnotetext{
${ }^{1}$ This fact is a primary consideration in much of the discussion over how such drivers should be classified-as contractors or as employees. If drivers tended to incorporate, the contractual relationship assumed between the driverprovider and the platform would be clear (contractor).

${ }^{2}$ While task-based employment existed well before the launch of Uber and Lyft, the arrival of internet ridehailing platforms is generally viewed as an inflection point in the development of the gig economy.
} 
We thus empirically use the arrival of UberX and Lyft to proxy for the appearance of gig economy opportunities, exploiting their staggered entry dates into U.S. cities. We utilize a difference-in-differences (D.D.) specification with fixed effects for location and time (quarteryear) as well as location-specific linear trends. Our D.D. specification allows us to capture macroeconomic changes, such as the Great Recession, technological improvements, as well as city-specific conditions such as city topology, industry mix, and so forth. The location-specific time trend captures location-specific pre-trends in our outcome variables that existed prior to the arrival of ridehailing. To capture potential time-and-city varying confounders, such as population changes or increases in employment or income, we further control for population levels and per capita income. Our results are robust to the inclusion of a variety of additional controls as well as location-specific quadratic trends, and hold for different pre-period lengths as well as when we restrict the sample solely to ever-treated locations.

We find an increase of $4-6 \%$ in new business registrations following the arrival of the gig economy in a city. Presumably, if the increase in new business launches is driven by the existence of gig economy income fallbacks, then the intensity of ridehailing adoption in a city should be related to the documented increase in our outcome variables. We proxy for the strength of ridehailing take-up in a city using the intensity of Google searches for terms such as "Uber" and "Lyft" in the treatment cities, a proxy that has been shown by past literature (e.g. Cramer and Krueger, 2016) to correlate strongly with driver adoption of the platforms. When we substitute the treatment indicator for post-gig economy-city with our ridehailing adoption intensity proxy for the city, we obtain similar results to those in our main specifications, with entrepreneurial entry increasing in the intensity of adoption of gig opportunities in the city.

A natural concern is that our proxy for gig economy arrival-ridehailing platformsspecifically entered into "entrepreneurial" cities. This does not appear to be the case. Using a hazard model approach, we document that the rollout timing of ridehailing platforms into cities is, as expected, predicted by per-capita income, population size and unemployment levels. It does not, however, appear to be predicted by levels entrepreneurial activity within a city.

We next proceed to examine the financing channel for new businesses. As documented by Guzmand and Stern (2019), the vast majority of new businesses launches are "traditional business entrepreneurship" (TBE) of the type described by Knight (1921). In contrast to innovation-driven

${ }^{3}$ In contrast, the high-growth, innovation-driven entrepreneurial activity that is typically financed by venture capitalists conforms more closely to the non-constraint view of Schumpeter. Schumpeter $(1934,1942)$ argues that the functions of the entrepreneur and the capitalist are separate. The entrepreneur plays the role of identifying potential 
entrepreneurship (IDE) ventures, which are typically financed via equity by angel and venture capital investors who bear the primary risk associated with the venture, TBE ventures are typically financed through entrepreneur wealth or through some form of debt, particularly small business lending. Thus, we focus our attention on SBA loans. We match businesses registered in the prior 6 (or 12) months to data on SBA loans made under the SBA's 7(a) programs. Consistent with our findings of a 4-6\% increase in realized business registrations, we document a corresponding increase of similar magnitude in small business lending to newly registered businesses after the arrival of the gig economy.

So far, the measures we have employed measure realized entrepreneurial activity. We next proceed to explore whether the presence of gig economy income opportunities can also be seen in indicators of interest in the possibility of launching a business. We measure entrepreneurial interest (expression of interest in entrepreneurship) using google searches for terms related to entrepreneurship, such as "how to start a business" or "how to incorporate." Consistent with our prior findings, the D.D. specification documents an approximate $7 \%$ increase in entrepreneurial interest surrounding the arrival of gig economy income opportunities in a city.

Our conceptual framework outlines two potential mechanisms that could drive such increases in entrepreneurial entry: an income supplement effect and an insurance effect. To test for evidence consistent with these channels, we interact our post-ridesharing variable with two sets of measures: (i) income levels and (ii) a proxy for uncertainty of economic conditions. The former can provide insight on the income supplement channel, while the second can provide insight regarding the insurance channel: if the associations we document are driven by gig economy income opportunities providing insurance against entrepreneurial-related income volatility, this insurance should be more valuable in locations where uncertainty of economic conditions is higher ex ante. We use the city-specific volatility of wage growth to proxy for the degree of economic uncertainty present in the location.

Consistent with the income supplement channel, we find that the documented patterns of increased entrepreneurial entry are larger in cities with lower income levels. Consistent with the notion of an insurance mechanism, we find that the effects of the arrival of the gig economy on entrepreneurial entry are more pronounced in locations where uncertainty was higher ex ante. Thus, the empirical patterns in the data provide support for both mechanisms, consistent with the conceptual framework.

arbitrage opportunities in the economy, while the part of modern capital markets is to find a capitalist willing to bear the risk for the entrepreneur. 
We go on to show that the pattern of where in the city these businesses open (geographic HHI) does not change post-gig economy arrival, suggesting that we are not merely picking up an increase in business opportunities due to the opening of new neighborhoods to transportation via ridehailing. The mix of new business types (traditional business versus innovation-driven business) also does not appear to be significantly altered by the arrival of the gig economy. Furthermore, while our D.D. specification with city-specific linear trends is designed to control for growth patterns in the city explicitly, we provide further evidence that the effect we document is not simply a manifestation of differential overall economic growth patterns. Specifically, we show that average weekly wages do not increase following the arrival of the gig economy, while our entrepreneurial activity measures do.

Finally, we round out our analysis by exploring heterogeneity in our outcomes across city characteristics along education levels, race and credit constraints. We find that our effects are largest in areas with lower education levels, higher fractions of Hispanic population, lower fractions of African-American population. When we look at credit constraints at the city level, we find a U-shaped pattern suggesting the effects are larger both when the population of a location is extremely credit-constrained and in locations where they face much lower constraints. This is consistent on the supply side with a loosening of the credit constraint and with increases in demand in less constrained areas.

Our study offers several contributions to the existing literature. First and foremost, our results speak to a growing literature on the factors that drive entry into entrepreneurship. Recently, there has been a great deal of concern regarding a decline in entrepreneurial entry and business dynamism (e.g. Decker et al. 2014), given the importance of entrepreneurial activity for economic growth (e.g. Haltiwanger et al., 2013). Our findings are consistent with those found in other contexts and countries when liquidity or credit constraints are relaxed or income fallbacks are provided: for example, Jensen et al (2014) show that a Danish mortgage reform that increases credit by $\$ 30 \mathrm{~K}$ leads to an increase in entry, while Gottlieb et al (2018) show that extended jobprotected maternity leave in Canada increases the likelihood of entry, Bellon et al. (2019) show that personal wealth windfalls from fracking increase entry into self-employment, and Hombert et al. (2020) show that provision of unemployment insurance to those entering into entrepreneurship increases new business formation. More broadly, our paper relates to a growing literature on entrepreneurial entry barriers, including personal wealth, government regulation, tax policy, and banking systems (see e.g. Evans and Jovanovic, 1989; Gentry and Hubbard, 2000; Hurst and 
Lusardi, 2004; Klapper et al., 2006; Cagetti and de Nardi, 2006; Aghion et al., 2007, and many more).

Our study further contributed to a growing literature on social and economic impacts of digitization (see e.g. Brynjolfsson and McAfee, 2014), both for worse (see, for example, Barrios et al. 2019; Hasan and Kumar, 2019) and for better. In this category, our also study contributes to a growing literature exploring the effects of gig economy. Most closely related to our study is Burtch et al. (2018), who examine the effect of the gig economy on Kickstarter projects and selfreported self-employment measures. Our findings of increased entry for incorporated businesses stand in contrast to their findings suggesting a move from ad hoc unincorporated self-employment to working for gig economy platforms.

In this vein, our work is closely related to studies such as Koustas (2018), Fos et al. (2019), and Jackson (2019) who demonstrate that the gig economy can serve as an income fallback in down states of the world such as unemployment or job loss. For ridehailing specifically, our work also related to studies such as Hall and Krueger (2018) and Chen et al. (2018), who explore the importance of flexibility to RH drivers. Our findings suggest that there are not only benefits to those who provide services for gig economy on-demand platforms, but also for those outside the platforms, as the existence of such opportunities provide insurance against volatility from entrepreneurial-related income.

The paper proceeds as follows. Section 2 provides an overview of the gig economy and outlines our conceptual framework. Section 3 describes our data and sample. Section 4 presents our empirical results. Section 5 concludes.

\section{THE GIG ECONOMY AND CONCEPTUAL FRAMEWORK}

\subsection{The Gig Economy}

The advent of the smartphone and the complementary technological advancement have reshaped the commercial landscape, providing consumers new ways to access the retail marketplace and providing workers with easy access to a new source of flexible work opportunities. The collection of markets that match providers to consumers on a gig (or job) basis, in support of on-demand commerce, has been coined "the gig economy." Companies such as Uber, Lyft, DoorDash, and Task Rabbit are prime examples of companies in this category that have arisen from such innovation. 
In the basic business model of the gig economy, gig workers serve as contractors to an ondemand company, providing services to the company's clients (Donovan et al., 2016). Prospective clients request services through an online platform or smartphone application that allows them to search for providers or to specify jobs. Providers (i.e., gig workers) engaged by the on-demand company then provide the requested services and are compensated for the jobs they perform.

While specific business models vary across the companies that control such platforms, with few exceptions, on-demand platform companies do not view their service providers as employees, but rather as independent contractors that utilize the platforms to obtain referrals and communicate with clients. In addition, many on-demand platform-companies offer providers some ability to select or refuse jobs, set their hours and level of participation, and control other aspects of their work. As a result, in some ways, the gig economy can be viewed as an expansion of traditional freelance work (i.e., ad hoc self-employed workers who generate income through a series of jobs and projects). Gig jobs, however, do differ from traditional freelance jobs in a number of ways. The user interface and brand built by the tech-platform company attracts clients, eliminating or reducing entry costs for providers (gig workers). These platforms may also attract potential service providers that have a wider variety of demographic, skill, and career characteristics. Because gig workers do not need to invest in establishing a company and marketing to a consumer base, operating costs may be lower, and as a result, participation in the gig market is often more transitory than the traditional freelancing market of old.

The advent of app platforms such as Uber, Lyft and others makes it easy for prospective providers to engage in gig work. These low barriers to entry allow gig work to substitute for other employment in down states of the world (Fos et al., 2019), or to provide supplemental income opportunities.

\subsection{Ridehailing}

We utilize the advent of ridehailing $(\mathrm{RH})$ platforms as the harbinger for the launch of the wider, platform-based on-demand gig economy. Uber was the first ridehailing firm in the United States, launching in San Francisco in May 2010, and was followed two years later by Lyft and Sidecar. Ridehailing then expanded rapidly across the country. By the end of 2014, RH firms operated in $80 \%$ of U.S. cities with a population of 100,000 or more. Much of the spread in RH was driven by the convenience for users, stemming from new technology easing the matching of riders and drivers and enabling seamless payment through an app. RH firms' exemptions from (or willful 
disregard for) taxi and livery restrictions allowed them to expand supply during periods of high demand and adjust prices to encourage more riders and drivers to participate in the market. ${ }^{4}$ This has in turn engendered backlash from advocacy groups and policymakers concerned with the effects of RH technology in their cities. ${ }^{5}$

\subsection{Conceptual Framework}

To better understand the potential effects of gig employment on entrepreneurial activity, we develop a simple conceptual framework. Our conceptual framework is rooted in the Knightian view that an individual's decision to enter entrepreneurship versus full-time wage-employment is determined by the relative returns offered by the two choices. Returns confer utility, and agents choose the option that maximizes their expected utility (Lucas, 1978; Kihlstrom and Laffont, 1979; Jovanovic, 1982). In our case, the whether an individual chooses to launch a new business is the result of an income choice that considers two elements that are theoretically impacted by the introduction of the gig economy and its associated income opportunities: entrepreneurial profit $(\Delta Y)$, and the volatility of entrepreneurial income in the area $\left(\sigma_{E}\right)$. For notational purposes, we define the quantity of new business launches in city $i$ in period $t$ as $N B_{i, t}$ and the new gigeconomy technology as $\theta$. New business launches can then be defined as:

$$
N B_{i, t}(\theta)=f\left(\Delta Y^{e}(\theta), \sigma_{E}(\theta)\right)
$$

where $\Delta Y^{e}(\theta)$ is defined as the difference between the income one earns as an entrepreneur in the new business and the income from a full-time wage job, for individuals in city $i$ in period $t$ (both potentially a function of whether the gig economy is available), and $\sigma_{E}$ is the volatility in the income from engaging in the entrepreneurial activity in city $i$ in period $t$. Studies on entrepreneurship have shown that new firm founders tend to come from the local area and same

\footnotetext{
${ }^{4}$ Many major ridehailing companies adjust pricing in real time to better match supply and demand, charging higher "surge pricing" fares during periods with high demand.

${ }^{5}$ In many ways, ridehailing has become the modern poster child for the classic battle between what are argued to be outdated regulations, supported by rent-seeking incumbents, and the introduction of a welfare-enhancing technology. Many new technologies face frictions that slow diffusion (Grubler, 1991). Parente and Prescott (1994) argue that one such friction is resistance on the part of sectoral interests. Indeed, emphasizing barriers to technology adoption, economic historians, such as Rosenberg and Birdzell (1986), argue that the reason why the West grew rich before the rest of the world was that active resistance to technology adoption was weaker there. Most economic histories of technological adoptions provide cases in which adoption was met with fierce resistance (Mokyr 1990).
} 
sector as the firm founded (Dahl and Sorenson, 2012; Guzman, 2019). Moreover, local conditions have been found to explain a large portion of new business entries (Glaeser and Kerr 2009). Thus, it is reasonable to think of the new business launch choice in terms of the current wage under fulltime employment and the expected profits as an independent entrepreneur in the entrepreneur's current location.

To examine the expected changes in entrepreneurial activity with respect to gig opportunities, we can derive the first order conditions of new business registrations with respect to gig opportunities:

$$
\frac{\partial N B(\theta)}{\partial \theta}=\frac{\partial N B}{\partial \Delta Y^{e}} \frac{\partial \Delta Y^{e}}{\partial \theta}+\frac{\partial N B}{\partial \sigma_{E}} \frac{\partial \sigma_{E}}{\partial \theta} .
$$

It is straight forward to see that $\frac{\partial N B_{i}}{\partial \Delta Y^{e}}$ is positive. We define $\Delta Y^{e}$ as:

$$
\Delta Y^{e}=y_{e}-y_{f e},
$$

where $y_{e}$ is income from entrepreneurial activity and $y_{f e}$ is the wage income that can be obtained under fulltime employment. Thus, an increase in $y_{e}$ or a decrease in $y_{f e}$ increases $\Delta Y^{e}$ and in turn increases the likelihood of new business launches. Intuitively, every additional increase in the difference between entrepreneurial income and fulltime employment income will increase the likelihood of an individual registering a new business.

Moreover, $\frac{\partial \Delta Y^{e}}{\partial \theta}$ is also likely to be positive, as the increased income opportunities in the downside case of the entrepreneurial activity leads to a higher expected income under entrepreneurial activity. Formally we can define $\Delta Y^{e}$ as a function of gig-economy opportunities $\theta$ as:

$$
\Delta Y^{e}(\theta)=y_{e(\theta)}-y_{f e(\theta)}
$$

From the above equation, it is not unreasonable to think that income from fulltime job employment is unlikely to be substantially affected by the advent of the gig economy. For example, 
a person working full time has limited hours to earn via gigs. As such, we can assume that $y_{f e(\theta=1)}=y_{f e(\theta=0)}$. The income that one earns as an entrepreneur, however, should be more likely to be affected by the existence of gig opportunities, as these may serve to supplement income during slow times. Thus, the potential entrepreneur's income is expected to be higher under gig economy opportunities than without $\left(y_{e(\theta=1)}>y_{e(\theta=0)}\right)$. As a result, the benefit from entrepreneurial income is larger with gig economy opportunities than without $\left(\Delta Y^{e}(\theta=1)>\right.$ $\left.\Delta Y^{e}(\theta=0)\right)^{6}$

In contrast, $\frac{\partial N B}{\partial \sigma_{E}}$, will be negative, as increased volatility in entrepreneurial income will increase the risk of earning income as an entrepreneur and would lead to less new business registrations. To see this, we can define $\sigma_{E}$ as:

$$
\sigma_{E}\left(\Delta Y^{e}(\theta)\right)=\int_{-\infty}^{\infty}\left(\Delta Y^{e}-\overline{\Delta Y^{e}}\right)^{2}\left(\Delta Y^{e}(\theta)\right) d \Delta Y^{e} .
$$

As $\sigma_{E}$ increases, risk-averse potential entrepreneurs should be less willing to leave their current full-time employment to launch a new firm. Yet, the flexibility associated with gig employment should allow entrepreneurs to increase their time spent on gig-activities in response to an unexpected decrease in entrepreneurial income, thereby decreasing income volatility (Farrell and Greig, 2016). We should thus expect, $\frac{\partial \sigma_{E}}{\partial \theta}$ to be negative. We can formally see this by defining $\sigma_{E}\left(\Delta Y^{e}(\theta=1)\right)$ and limiting the potential entrepreneur's low outcomes to $\varepsilon>-\infty$. Thus, we can examine the effects of the side hustle on the volatility of entrepreneurial income formally as:

$$
\begin{aligned}
& \sigma_{E}\left(\Delta Y^{e}(\theta=0)\right) \\
&=\int_{-\infty}^{\infty}\left(\Delta Y^{e}-\overline{\Delta Y^{e}}\right)^{2}\left(\Delta Y^{e}(\theta)\right) d \Delta Y^{e} \\
&>\int_{\varepsilon}^{\infty}\left(\Delta Y^{e}-\overline{\Delta Y^{e}}\right)^{2}\left(\Delta Y^{e}(\theta)\right) d \Delta Y^{e}+\int_{-\infty}^{\varepsilon}\left(\Delta Y^{e}-\overline{\Delta Y^{e}}\right)^{2}\left(\Delta Y^{e}(\theta)\right) d \Delta Y^{e} \\
&=\sigma_{E}\left(\Delta Y^{e}(\theta=1)\right)
\end{aligned}
$$

From this derivation, it is straight forward to see that $\sigma_{E}\left(\Delta Y^{e}(\theta=1)\right)<\sigma_{E}\left(\Delta Y^{e}(\theta=0)\right)$. The reduction in variance brought about by the advent of gig opportunities would then imply that the overall effect of $\frac{\partial N B}{\partial \sigma_{E}} \frac{\partial \sigma_{E}}{\partial \theta}$ should be positive - at least to the extent that the flexible income

\footnotetext{
${ }^{6}$ Alternatively, one could assume that both fulltime and entrepreneurial income might be positively affected by the gig economy, but the entrepreneurial income is likely to be more affected - and we should also thus see an increase in ridehailing activity leading to an increase in new business launches.
} 
opportunities from the gig economy are large enough to reduce the overall variance of expected entrepreneurial income. Thus, under this simple conceptual framework, the overall effect of ridehailing on new business launches is likely to be positive. We go on to empirically explore these hypothesized effects.

\section{DATA AND SAMPLE}

Our sample consists of all incorporated "places" 7 in the continental United States with population greater than or equal to 10,000 in $2010 .{ }^{8}$ Our full sample covers the period 2000 to 2016; all results are robust to employing shorter pre-RH sample windows. The sample stops in 2016 due to that being the last year of availability in the SCP data. Our list of incorporated places is obtained from the Census Bureau and covers all self-governing cities, boroughs, towns, and villages in the United States. ${ }^{9}$ (For ease of interpretation, we interchangeably refer to these as "cities" or "locations" throughout the text.) Our observations are measured at the quarterly level. The full sample contains 201,212 quarterly observations on 2,959 "places" from 2000 to 2016, among which 1,193 adopt RH prior to 2016. Figure 3 shows the diffusion of RH across the United States, by cities and population. Diffusion of RH across U.S. cities began slowly, accelerating rapidly after 2013. Diffusion by population follows a standard S-curve, consistent with general historical patterns of new technology diffusion. ${ }^{10}$

\subsection{Ridehailing Launch and Driver Enrollment Intensity}

Data on RH launch dates for each city are obtained directly from Uber and Lyft. ${ }^{11}$ The companies provided dates of service launch for each type of service launched: (i) UberBlack/UberTaxi, which allows customers to hail a livery or taxi vehicle; (ii) UberX/Lyft, which allow customers to hail regular cars driven by driver-partners; and (iii) UberPool/Lyft Line,

\footnotetext{
${ }^{7}$ We use incorporated places, rather than Census Designated Places (CDPs), because CDP annual population estimates are not readily available, except by individual place download, whereas population data is available for incorporated places for mass download through the census.

${ }^{8}$ Some places in our sample had lower populations than 10,000 during the sample period, most notably during the period of 2001-2010. We impose the cutoff on population as measured in 2010. As an example, consider Hutto, Texas, a suburb of the Austin-RoundRock metro area. In 2001, Hutto had a population of 3,030, the lowest in our sample. By 2010, it had grown to over 14,000, mimicking the growth of the Austin metro area. As it has population above 10,000 in 2010, it is included in our sample. Our results are robust to permutations to this cutoff.

${ }^{9}$ https://www.census.gov/content/dam/Census/data/developers/understandingplace.pdf

${ }^{10}$ In the Online Appendix, we further demonstrate the robustness of our results to using shorter pre-sample periods.

${ }^{11}$ In this version, we use the exact cities indicated by Uber and Lyft, even if we suspect or believe that the launch covered adjacent cities as well (e.g., San Francisco launched in 2010, and there is no separate launch date for San Jose or Palo Alto). Since this means some places we include in our control may in fact be treated in later years in the sample as service expands slowly out beyond original boundaries, we are biasing against finding an effect of treatment.
} 
which allow customers to share a hailed vehicle with others. We focus on UberX/Lyft and UberPool/Lyft Line, as these are the services that opened up gig economy opportunities to any driver meeting minimal requirements. ${ }^{12}$ We merge these dates with Census Bureau's incorporated place directory in 2010 .

While data on driver enrollment and usage is not publicly available, other researchers have shown a strong correlation between Google trends for searches for RH keywords and actual driver uptake (Cramer and Krueger, 2016). To measure the intensity of RH adoption, we thus follow the spirit of the work of Cramer and Krueger (2016) and Hall et al. (2018) and use Google searches for the terms "Uber," "Lyft," and "rideshare." 13 The standard Google Trends index, which scales results from 0 to 100 based on the most popular term entered, does not easily allow comparisons across geographic areas and time periods. Instead, we use data from the Google Health Trends API, which describes how often a specific search term is entered relative to the total search volume on Google's search engine within a geographic region and time range, and returns the probability of a search session that includes the corresponding term for that region and time period. This makes comparisons across locations and time feasible. ${ }^{14}$ We track trends for searches for these terms using the Google Health Trends API for all Nielsen Designated Market Areas (DMAs) at monthly frequency from January 2004 to December 2016. We aggregate the data to the quarter level and match the DMAs to Census incorporated places using a crosswalk provided by Nielsen. Thus, in specifications that use log search share as a proxy for driver enrollment intensity, we interpret the coefficients in terms of percentage change in search share.

\subsection{Entrepreneurial Measures}

We utilize three main outcome measures for our analysis of entrepreneurial activity. The first of these measures captures new business launches. The second provides a measure of financing for the types of new businesses we would expect to see launched under the Knightian-inspired conceptual model: small business loans to new businesses. Finally, we explore whether increased interest in entrepreneurship is apparent more generally, utilizing internet search share for terms related to starting a new business, a measure we term entrepreneurial interest.

\footnotetext{
12 In contrast, driving for Uber Black or Uber Taxi required a chauffer license and a black car or taxi medallion.

${ }^{13}$ We use the freebase identifiers for term "Uber" (/m/0gx0wlr) and "Lyft" (/m/0wdpqnj). Freebase identifiers denote all searches that were classified to be about this topic.

14 These probabilities are calculated on a uniformly distributed random sample of $10 \%-15 \%$ of Google web searches. Mathematically, the numbers returned from the Google Trend API can be officially written as:

Value $_{[\text {time,term restriction }]}=P($ term - restriction $\mid$ time and geo - restriction $) * 10 \mathrm{M}$

This probability is multiplied by 10 million in order to be more human readable.
} 


\subsubsection{New Business Launches}

Our first outcome measure is the quantity of new business launches, measured using business registrations by location and time period. For this purpose, we obtain data on new, for-profit business registrations from the Startup Cartography Project (SCP, Guzman and Stern, 2019). The SCP leverages business registration records, which are public records created when an individual register's a new business as a corporation, LLC or partnership. Importantly, as noted by Guzman and Stern (2019), while it is possible to found a new business without business registration (e.g., a sole proprietorship), the benefits of registration are substantial, and include limited liability, various tax benefits, the ability to issue and trade ownership shares, and credibility with potential customers. Furthermore, all corporations, partnerships, and limited liability companies must register with a Secretary of State or equivalent in order to take advantage of these benefits: the act of registering the firm triggers the legal creation of the company. As such, these records reflect the population of incorporated businesses operating in a location (which may differ from their state of incorporation) that take a form that is a practical prerequisite for growth.

The SCP dataset provided to us covers 49 states plus the District of Columbia over the period 2001 to 2014, and 47 States plus the District of Columbia from 2015 to 2016. For each state, the SCP data includes records on the complete population of firms satisfying one of the following two conditions: (i) a for-profit firm physically located in the local jurisdiction, or (ii) a for-profit firm whose jurisdiction is in Delaware but whose principal office address is in the local state.

The SCP dataset provides a number of variables of interest to entrepreneurship researchers. We focus here on two specifically: (i) the quantity of new business registrations in a Census incorporated place in a given year and quarter, and (ii) an Entrepreneurial Quality Index (EQI), which is a measure of average quality within any given group of firms, and represents a prediction for the probability of a growth outcome for a firm within a specified population of start-ups in a specific period (More information on this measure can be found in Guzman and Stern 2019).

\subsubsection{Lending to New Businesses}

Our second outcome measure is the volume of lending under the Small Business Administration's (SBA) 7(a) loan program. The Small Business Administration (SBA) 7(a) Loan Guarantee program is one of the most popular loan programs offered by the agency. Under the program, a 7(a) loan-guarantee is provided to lenders to make them more willing to lend money to 
small businesses with weaknesses in their loan applications, such as new businesses startups that lack the cash flow history to provide a lender with the assurance of continued ability to pay back a loan. 7(a) loans may be used for such business purposes as purchasing land or buildings, equipment, machinery or supplies; for long-term or short-term working capital; for refinancing; or for the purchase of an existing business. They are limited to a maximum of $\$ 2$ million, with an SBA loan guarantee of $75 \%$. The terms of SBA 7 (a) loans are up to 25 years for real estate and equipment and seven years for working capital, and interest rates are set and capped based on the prime rate, the size of the loan, and the maturity of the loan.

We utilize data on SBA lending under the 7(a)-guarantee program that is released quarterly under the Freedom of Information Act. Use the business name and location for each SBA loan in the dataset, the Startup Cartography Project then matched the SBA loans to their business registration records in the same location, providing us with business registration data for approximately half the loans in the dataset. As each business registration contains a date of registration, for each location and quarter, we can then calculate two measures: the number of loans made to new businesses registered in the prior six months, and the number of loans made to new businesses registered in the prior twelve months.

\subsubsection{Entrepreneurial Interest}

Our final outcome measure, which we dub Entrepreneurial Interest, utilizes the google Health Trends interface to extract data on searches for entrepreneurship related terms such as "how to start a business" and "how to incorporate." 15 As previously noted, the Google Health Trends API describes how often a specific search term is entered relative to the total search volume on Google search engine within a geographic region and time range, and returns the probability of a search session that includes the corresponding term, which makes comparisons across locations and time feasible. We track trends for searches for these terms using the Google Health Trends API for all Nielsen Designated Market Areas (DMAs) at monthly frequency from January 2004 to December 2016. We aggregate the data to the quarter level and match the DMAs to Census incorporated places using a crosswalk provided by Nielsen.

\footnotetext{
15 Specifically, we use the terms: "start a business," "start your own business," "start a company," "how to incorporate," "entrepreneurship," "become an entrepreneur," and "small business loan."
} 
Using this data, we then define three outcome measures: (i) whether a city is in the top quartile of cities for probability of search for entrepreneurship-related terms in that period; (ii) whether a city is in the bottom quartile of cities for probability of search for entrepreneurship-related terms in that period; and (iii) actual search share.

\subsection{Control Variables and City Characteristics}

We use a number of measures to explore heterogeneity by city characteristics and as control variables in our models. We obtain annual city population estimates and population density from the U.S. Census and annual county income per capita from the Bureau of Economic Analysis. Household vehicle ownership and means of transportation to work at the city level are gathered from the 2010 American Communities Survey. Controlling for population, per capita income, and unemployment rate - which vary by time and location - are of first order importance as they provide a proxy for specific concerning confounders.

To examine how variation in individuals' credit constraints affect the impact of the gig economy on entrepreneurship, we use a dataset of anonymized individual credit bureau records in 2010 to further construct several ex ante proxies for income and credit constraints. The credit bureau data contain a $1 \%$ representative sample of all U.S. residents selected based on the last two digits of their social security number. This sampling procedure produces a random sample of individuals because the Social Security Administration sequentially assigns the last 4 digits of social security numbers to new applicants regardless of geographical location. We calculate the annual average personal income and credit score for each city, as well as the fraction of low income and subprime borrowers. Following the cutoff used by the credit bureau, we identify an individual as a subprime borrower if his or her credit score is below 660 . Approximately $44 \%$ of individuals in our sample are subprime.

To explore heterogeneity by demographic characteristics, we develop city-level measures of education levesl using the Census Bureau's 5-year American Community Survey data. We obtain both the fraction of individuals with a high-school degree and the fraction of individuals with a bachelor's degree for each city in 2010. We also calculate county-level racial and ethnic composition measures, such as the fraction of Hispanic population and the fraction of Black and African American population, using Census Bureau's 2010 county population estimates.

\subsection{Economic Uncertainty}

Our conceptual model relates the economic uncertainty in an area and flexible gig-economy opportunities to new business formation. Ideally, we would use variation in economic profits in an 
area to proxy for economic uncertainty. Due to the lack of availability of quarterly data on business profits, we use variation in wage growth as a proxy. Conceptually, we can think of economic profits as reflecting demand shocks to industries, which in turn also lead to variation in wage growth. More concretely, under a rent-sharing perspective, whenever there is a demand shock that leads to change in profits, this change is shared between the firm and labor (Kline et al., 2019).

To operationalize this economic uncertainty proxy by constructing a measure of the volatility in wage growth in each location. We utilize data from the Bureau of Labor Statistics (BLS) Quarterly Census of Employment and Wages (QCEW) for this purpose. Wage growth volatility is computed as the sum of the variances and covariances of the wage growth rate in the various industry sectors, weighted by the employment share of each individual sector. We compute this measure at the county level.

For our computations, we derive a variance-covariance matrix from a trend-adjusted time series of county-industry employment data. Mathematically, the measure of wage growth volatility for the portfolio of industries in a given city is then expressed as:

$$
\sigma_{p}^{2}=\sum_{i} w_{i}^{2} \sigma_{i}^{2}+\sum_{i \neq j} \sum_{i \neq j} w_{i} w_{j} \sigma_{i j}
$$

where $w_{j}$ denotes the proportion of total employment in industry $\mathrm{j}, \sigma_{j}^{2}$ denotes the variance of wage growth rate in industry $\mathrm{j}$, and $p$ denotes city.

In Figure 2, we graph the relationship between our wage growth volatility measure and new business registration. We absorb time and location. As can be seen from the scatter plot, the relationship between wage growth volatility and entrepreneurial entry is negative, as expected.

\subsection{Summary Statistics}

Table 1, Panel A presents summary statistics for the places in our sample over the sample period. The places average 54,348 in population and have an income per capita of $\$ 39,300$. Prior to the advent of ridehailing in $2010,44.1 \%$ of borrowers in our sample places were subprime, $49 \%$ were low income, $85.6 \%$ have at least a high school degree, and $28.6 \%$ have at least a Bachelors degree. As can be seen from the distributional statistics in the table, there is wide variation across all these characteristics across the sample. The table further presents summary statistics on our entrepreneurial activity measures over the sample period. 


\section{EMPIRICAL ANALYSIS}

To assess the impact of the insurance against entrepreneurial income-related volatility on entrepreneurial activity, we employ a standard generalized difference-in-differences approach. We index cities by $c$ and time by $t$. We estimate models of the following form:

$$
\log \left(1+\text { outcome }_{t, c}\right)=\alpha_{c}+\gamma_{t}+\beta^{\prime} X_{t, c}+\theta_{c} t+\delta P O S T_{t} * \text { TREATE }_{c}+\varepsilon_{t, c},
$$

where outcome $e_{t, c}$ is one of our measures of entrepreneurial interest or activity in city $c$ in quarter $t, \propto_{c}$ is a city fixed effect, $\gamma_{t}$ is quarter-year fixed effect, $X_{t, c}$ is a vector of time-varying, city specific control variables (lagged one quarter), and $\theta_{c} t$ is a city-specific linear time trend.

Certainly, ridehailing companies' choice of cities to launch in first was probably not random. The main concern for our identification approach then centers around whether Uber and Lyft were specifically selecting cities in which to roll out services based on the trends in entrepreneurial activity and business registration in that city. In Table 2, we formally model the timing of ridehailing arrival in cities using a Cox proportional hazard model. While there is positive selection on population and per-capita income, as might be expected, empirically, however, we observe no significant loading on either new business registrations or SBA loans to newly registered businesses. Thus, it appears to be reasonable to utilize the staggered rollout for the purposes of our analysis, controlling for population and per-capita income. We further include location-specific linear trends. ${ }^{16}$

We use robust standard errors, clustered at the city level. Our observations are at the quarterly level, and cover the first quarter of 2001 through the fourth quarter of 2016. For each outcome measure, we present estimates for models estimated on the full sample (2001-2016), a subsample using a shorter pre-period (2005-2016) and restricting the sample only to those cities that are evertreated by ridehailing during our sample period. This last specification is meant to assuage concerns that our estimates may be driven solely by the differences between never-treated and ever-treated cities.

\subsection{New Business Registration}

We begin by exploring new business launches, using registrations of new companies. Table 2 employs our DD specification, where our outcome measure is the natural logarithm of one plus the number of new business registrations in the city/quarter. For brevity, we report only the coefficient on the variable of interest- $P O S T_{t} * T R E A T E D_{c}$ in the table. We report OLS

\footnotetext{
${ }^{16}$ For robustness, we also estimate all our models with the inclusion of a location-specific quadratic trend as well, with qualitatively similar results.
} 
specifications, but our results remain robust to the use of count models instead (though we note that interpretation of interaction terms in such models is not straightforward and cannot simply be determined by the sign of the coefficient - see Ai and Norton 2003). We estimate four models: column (1) presents estimates from the full sample period, column (2) shortens the sample period to post 2005, column (3) restricts to solely ever-treated cities, and column (4) uses only evertreated cities, but with the sample post 2005. The second two of these models are meant to assuage concerns that any results might be driven solely by differences between ever-treated and nevertreated cities.

Across all four models, we observe a similar pattern. The coefficient on $P O S T_{t} * T R E A T E D_{c}$ ranges from 0.026 to 0.054 , depending on the sample employed, consistent with the arrival of the gig economy being associated with an increase of approximately 3 to $5 \%$ in new business registrations. Figure 2 graphs the coefficients at the annual level around the entry point; the graph suggests that the parallel trends assumption holds.

In the main models presented in Table 2, we employ the first launch of a RH service, irrespective of the type of service, as our treatment date. Take up of these services, however, is likely to intensify over time. To explore this issue, we now interact our TREATMENT indicator with the intensity of Google searches for ridehailing-related terms measure and re-estimate our models. Table 3 replicates the models in Table 2, but with the addition of an additional interaction with this adoption intensity proxy. The resulting estimates are consistent with an increase in business registrations following an increase in our Google Trends adoption intensity measure. For all four models, the coefficient estimate on TREAT *POST *INTENSITY is positive and statistically significant. Thus, as our proxy for gig economy adoption intensity (Google trends search share for ridehailing keywords) increases, so do new business launches. ${ }^{17}$

Of course, one concern is that the order of entry for ridehailing companies into cities is not random. To interpret our estimates with an eye towards causality, business registrations themselves would ideally not be a predictor of entry. Table 4 presents estimates from a Cox proportional hazards model for ridehailing entry into cities. As can be seen from the table, population and

\footnotetext{
${ }^{17}$ An ideal additional test would be to look at U.S. cities where RH was introduced and then withdrawn. Unfortunately, these cities are few, and the circumstances do not allow for the types of tests we would want. For example, Uber and Lyft both withdrew from the Austin market at one point in 2016 in a regulatory dispute, but at least five other RH services were still operating and took up the slack. Uber and Lyft then returned to the Austin market within a year, after Texas passed HB100, creating looser statewide rules that superseded Austin's (their return led to immediate massive drops in volume for the competitors that sprung up in their absence). In Las Vegas, the other city we are aware of, RH was introduced, then outlawed after only one month of service.
} 
income strongly predict entry timing, while there is no statistically significant loading on new business registrations.

\subsection{Loans to Newly Registered Businesses}

Next, we explore turn to our second outcome measure, which is based in the financing channel for new businesses. We do this using SBA 7(a) small business loans to newly registered businesses, as small, traditional businesses represent the vast majority of new business starts (as opposed to innovation-driven startups, which are typically funded by venture capital and are much rarer).

Table 5 presents estimates from models similar to those in Tables 2, using the SBA loan counts to new businesses registered in the last 6 (Panel A) or 12 months (Panel B). Here, once again, we see that the emergence of the gig economy, in the form of entry of a RH platform, is associated with an increase in loans to new businesses, consistent with — and of a magnitude corresponding to - the increase in new business registrations suggested by the models in Table 4 and predicted by the increase in entrepreneurial interest suggested by the models in Table 3. Thus, across all three sets of outcome measures - interest, realized starts, and financing — we observe a consistent pattern: the arrival of the gig economy is associated with an increase in entrepreneurial entry activity, consistent with the hypothesis that the gig economy serves as an income supplement and/or insurance against entrepreneurial-related income volatility.

\subsection{Entrepreneurial Interest}

As we have seen in the prior two subsections, the arrival of the platform-enabled gig economy appears to be associated with a significant increase in entrepreneurial entry. We next turn to a measure which may capture interest in considering entrepreneurial entry more broadly: internet searches for terms and phrases directly related to launching a business - which we term entrepreneurial interest. In Figure 3, we explore the relationship between entrepreneurship search share and business registrations. Figure 3 presents a scatter plot of business registrations against search share for entrepreneurial terms, for the pre-ridehail subsample and the post-ridehail subsample. For both subsamples, the relationship is, as expected, upwards sloping. In the postridehail subsample, however, the slope of the relationship steepens.

Table 6 employs the natural logarithm of $1+$ search share for entrepreneurship-related terms as the outcome measure for entrepreneurial interest. As before, column (1) presents estimates using the full sample, column (2) restricts the sample to post-2005, column (3) restricts the sample to the ever-treated sample of cities, and column (4) imposes both the post-2005 and ever-treated filters. Regardless of specification, we observe a similar pattern of increase in search for entrepreneurial- 
related terms after the arrival of the gig economy: the estimates suggest an increase in the range of $7 \%$ to $13 \%$ in the share of search for entrepreneurship-related terms.

\subsection{Mechanisms: Income and Insurance}

We next proceed to dig deeper into the plausibility of the two mechanisms suggesting by our conceptual framework. We begin by examining the income supplement channel. In Table 7 Panel A, we employ two measures to test whether the effect of the arrival of the gig economy is, in fact, larger in areas where the income supplement may be most valuable: areas with low personal income pre-gig economy arrrival. Panel A presents the results of fully interacted models which include the interaction of this measure with the TREATMENT * POST variable. We standardize these measures to have a mean of zero and a standard deviation of one to ease interpretation of the coefficients. Because these proxies are measured once-per-city for the pre-period rather than at the annual level, the lower order terms for the income measures themselves are absorbed in the city FE. Consistent with the predictions of the conceptual model with regards to the income supplement channel, we observe that the effects are higher in low income areas, regardless of which proxy is employed. A one standard deviation increase in average ex ante personal income in a city is associated with a 2 percentage point reduction off the main TREATMENT *POST effect of 5 to $6 \%$.

Next, we turn to the insurance channel. Presumably, if the gig economy is acting as a form of insurance for would-be entrepreneurs, we would expect its effects on entrepreneurial activity to be stronger in locations where such insurance is more valuable: locations where economic uncertainty (and in turn, entrepreneurial income uncertainty), is higher. In Table 7 Panel B, we utilize our proxy for economic uncertainty - the volatility of wage growth in the location - and estimate similar fully interacted models including the interaction of a standardized version of this measure with the TREATMENT * POST variable into our models. We measure wage growth volatility for each city using all quarters up to the quarter before entry (or all quarters, if no entry occurs during the sample period). Because this measure in not at the annual level, but measured once per city, the lower order term (pre-entry wage growth volatility itself) is absorbed in the city FE. Consistent with our conceptual framework, the models in Table 7 indicate that in cities with higher ex ante economic uncertainty, the positive effects of the arrival of the gig economy are higher in cities with higher ex ante economic uncertainty, translating into an additional 1 to 2 percentage point increase in new business registrations for a one standard deviation increase in ex ante economic uncertainty, on top of the main effect. This bolsters the view that the gig economy provides insurance for would-be entrepreneurs. 


\subsection{Nature of Entrepreneurial Activity}

Finally, we explore whether the gig economy has compositional effects on the type of business launched. As noted by Levine and Rubinstein $(2017,2018)$ and Guzman and Stern (2019), there is considerable heterogeneity in both the goal of entrants into entrepreneurship and in the types of companies they launch. These range from small business entrepreneurs who undertake entrepreneurship for non-pecuniary reasons, such as leisure or flexibility (Hurst and Pugsley, 2011), to entrepreneurs like Mark Zuckerberg or Peter Thiel, who launch innovation-driven startups with the goal of high growth. Guzman and Stern $(2015,2019)$ combine the comprehensive business registration data used earlier in this paper with predictive analytics to compute estimates of entrepreneurial "quality" over time. For the purposes of our analysis, SCP provided us with their Entrepreneurial Quality Index (EQI) — which measures the predicted probability that a new business launched in a location and time period will have a high growth outcome-computed at the county-quarter level. We can then use the EQI measure to assess compositional effects: if EQI increases post-RH arrival, this suggests that the share of innovation-driven startups in a treated location goes up post gig economy arrival. If EQI decreases, it suggests the share of traditional, small business entrepreneurship has gone up.

In Table 8, Panel A, we estimate our models using EQI as the outcome variable. As can be seen from the models in the table, we observe no significant change in EQI in the treated cities post gig economy arrival, suggesting that the composition of types of entrepreneurs in a city is not significantly altered by the gig economy.

In Panel B, we explore another aspect of the new entrepreneurial activity: geographic dispersion across the city. One concern is that our prior estimations are picking up not a general effect of the gig economy, but rather a specific effect of ridehailing, namely the ability of this new transportation mode to open opportunities for businesses in new neighborhoods that previously suffered from a lack of easy transportation access. In Panel B of Table 8, we estimate our DD models using as an outcome measure the Herschman-Herfindahl Index by zip code within city, as a measure of geographic dispersion of where businesses launch. More specifically, the dependent variable in Panel B measures the concentration of new business registration in a city-quarter, measured using an HHI index that equals to the sum of the zip shares of business registration in a city squared. We observe no significant change in geographic concentration in the treated cities post gig economy arrival - if anything, we see a slight increase in concentration — suggesting that the geographic concentration of entrepreneurs in a city is not significantly altered by the gig economy. 


\subsection{Are We Just Capturing City Growth?}

One concern is that despite our strict specification, perhaps somehow, we are still just capturing different trends in economic growth in cities. We can assuage these concerns directly. If our findings were driven solely by improvements in economic conditions that are not captured by the D.D. specification, we would expect to see a similar effect if we replaced our business registrations outcomes with a measure such as local employment wages. In Table 9, we estimate models using average weekly wage as the outcome measure, and in similar specifications to the previous tables. Not only do we observe no corresponding increase in average weekly wages, the coefficients are, in fact, negative, suggesting that our observed increases in entrepreneurial activity are driven by general growth in economic activity.

\subsection{Heterogeneity}

Finally, we explore whether the gig economy differentially bolsters entrepreneurial entry in cities with different underlying demographic and socio-economic characteristics. Specifically, we focus on education, race, credit constraints and income. In Table 10, we break out our results across a variety of city characteristics. For each characteristic, we assign cities to quartiles based on the measures for each characteristic calculated in 2010. We take these measures primarily from the American Community Survey. We then re-estimate our models, interacting POST* TREATMENT with the four quartile indicators for each city characteristic. The specifications include location and year-quarter fixed effects, a location-specific linear time trend, and control variables.

For education levels, we observe the gig economy effect on entrepreneurial entry is concentrated in cities with a low fraction of population having obtained a high school (column (1)) or bachelor degree (column (2)). This would be consistent with the gig economy insurance effect being more valuable for lower education entrepreneurs. When we look at race, we find the effect is higher in cities with a higher fraction of Hispanic population (column (3)), and in cities in the middle of the distribution for Black and African American population (column (4)). The effect is actually negative and significant coefficient in cities in the top quartile of Black and African American population share. We take no stance the mechanism for the observed heterogeneity for race; future research may wish to explore these patterns in more detail.

We next turn to socio-economic characteristics. In columns (5) and (6) we look at credit constraints, measured as the average credit score in the city (column (5)) and the fraction of subprime borrowers (credit score below 660) in the city (column (6)). Our observed effects on 
entrepreneurial entry are concentrated in the lowest and highest quartiles of credit score: the large effect in the lowest quartile of credit score and highest quartile of fraction of subprime borrowers are consistent with the Knightian view of risk bearing in entrepreneurship. We observe an equally large in the least constrained areas (Q4 credit score, Q1 subprime fraction) where the demand effect likely dominates.

\section{CONCLUSION}

Economists since Adam Smith have emphasized the importance of entrepreneurs and new business formation to the economy. Policymakers continuously seek for ways to stimulate entrepreneurial activity in their local regions. In this paper, we shed light on a development in the digital economy that has positive spillover effects on entrepreneurial activity: the advent of ondemand gig economy platforms. Our findings suggest that the provision of income supplements and insurance against entrepreneurial-related income volatility serves to increase entrepreneurial activity and galvanize would-be entrepreneurs to engage in new business formation.

While much of the literature on the effects of the gig economy focuses on its direct impact on gig workers, our work joins a small emerging literature exploring the spillover effects from the advent of large-scale gig platforms (e.g., Koustas, 2018; Fos et al., 2019). Our findings suggest that the gig economy plays a substantial role in spurring entrepreneurial entry by providing a form of insurance against entrepreneurial related-income volatility in the form of income fallbacks, and by providing a potential income supplement to those who engage in entrepreneurial activity. Both these mechanisms serve to reduce the risk of launching a new business. This benefit is particularly strong in cities with worse socioeconomic conditions, where policy makers may be especially interested in encouraging new entrepreneurial activity. 


\section{REFERENCES}

Aghion, Philippe, Thibault Fally, and Stefano Scarpetta. "Credit constraints as a barrier to the entry and post-entry growth of firms." Economic Policy 22 (2007): 732-779.

Ai, Chunrong, and Edward C. Norton. "Interaction terms in logit and probit models." Economics Letters 80 (2003): 123-129.

Barrios, John Manuel, Yael V. Hochberg, and Hanyi Yi. "The cost of convenience: Ridesharing and traffic fatalities." Available at SSRN 3361227 (2019).

Bellon, Aymeric, Erik P. Gilje, J. Anthony Cookson, and Rawley Z. Heimer. "Personal wealth and self-employment." Working paper (2019).

Brynjolfsson, Erik, and Andrew McAfee. "The second machine age: Work, progress, and prosperity in a time of brilliant technologies." WW Norton \& Company (2014).

Burtch, Gordon, Seth Carnahan, and Brad N. Greenwood. "Can you gig it? An empirical examination of the gig economy and entrepreneurial activity." Management Science 64 (2018): 5497-5520.

Cagetti, Marco, and Mariacristina De Nardi. "Entrepreneurship, frictions, and wealth." Journal of Political Economy 114 (2006): 835-870.

Chen, M, Keith, Judith A. Chevalier, Peter E. Rossi, and Emily Oehlsen. "The value of flexible work: evidence from uber drivers." NBER Working Paper No. w23296 (2017).

Cramer, Judd, and Alan B. Krueger. "Disruptive change in the taxi business: the case of uber." American Economic Review 106 (2016):177-182.

Dahl, Michael S., and Olav Sorenson. "Home sweet home: Entrepreneurs' location choices and the performance of their ventures." Management Science 58 (2012): 1059-1071.

Decker, Ryan, John Haltiwanger, Ron Jarmin, and Javier Miranda. "The secular decline in business dynamism in the US." University of Maryland Working Paper (2014).

Donovan, Sarah A., David H. Bradley, and Jon O. Shimabukuru. "What does the gig economy mean for workers?" (2016).

Evans, David S., and Boyan Jovanovic. "An estimated model of entrepreneurial choice under liquidity constraints." Journal of Political Economy 97 (1989): 808-827.

Farrell, Diana, Fiona Greig. "Paychecks, paydays, and the online platform economy: Big data on income volatility." Available at SSRN 2911293 (2016).

Fos, Vyacheslav, Naser Hamdi, Ankit Kalda, and Jordan Nickerson. "Gig-Labor: Trading safety nets for steering wheels." Available at SSRN 3414041 (2019).

Gentry, William M., and R. Glenn Hubbard. "Tax policy and entrepreneurial entry." American Economic Review 90 (2000): 283-287.

Glaeser, Edward L., and William R. Kerr. "Local industrial conditions and entrepreneurship: how much of the spatial distribution can we explain?" Journal of Economics \& Management Strategy 18 (2009): 623-663. 
Gottlieb, Joshua D., Townsend, Richard R., and $\mathrm{Xu}$, Ting. "Does career risk deter potential entrepreneurs?" SSRN Working Paper (2018).

Guzman, Jorge. "Go west young firm: agglomeration and embeddedness in startup migrations to Silicon Valley.” Columbia Business School Research Paper (2019).

Guzman, Jorge, and Scott Stern. “Where is silicon valley?” Science 347 (2015): 606-609.

Guzman, Jorge, and Scott Stern. "The state of American entrepreneurship: new estimates of the quantity and quality of entrepreneurship for 15 us states, 1988-2014." NBER Working Paper No. w22095 (2019).

Hall, Jonathan V., and Alan B. Krueger. “An analysis of the labor market for uber's driver-partners in the united states.” ILR Review 71 (2017): 705-732.

Hall, Jonathan D., Craig Palsson, and Joseph Price. "Is Uber a substitute or complement for public transit?" Journal of Urban Economics 108 (2018): 36-50.

Hasan, Sharique, and Anuj Kumar. "Digitization and divergence: Online school ratings and segregation in America." Available at SSRN 3265316 (2019).

Haltiwanger, John, Ron S. Jarmin, and Javier Miranda. "Who creates jobs? Small versus large versus young." Review of Economics and Statistics 95 (2013): 347-361.

Hombert, Johan, Antoinette Schoar, David Sraer, and David Thesmar, "Can Unemployment Insurance Spur Entrepreneurial Activity? Evidence from France." The Journal of Finance (forthcoming).

Hurst, Erik, and Annamaria Lusardi. "Liquidity constraints, household wealth, and entrepreneurship.” Journal of Political Economy 112 (2004): 319-347.

Hurst, Erik, and Benjamin W. Pugsley. "What do small businesses do?" NBER Working Paper No. w17041 (2011).

Jensen, Thais Lærkholm, Søren Leth-Petersen, and Ramana Nanda. "Housing collateral, credit constraints and entrepreneurship-evidence from a mortgage reform," NBER Working Paper No. w20583 (2014).

Jackson, Emilie. "Availability of the gig economy and long run labor supply effects for the unemployed". Working paper (2019).

Jovanovic, Boyan. "Selection and the evolution of industry." Econometrica: Journal of the Econometric Society (1982): 649-670.

Kihlstrom, Richard E., and Jean-Jacques Laffont. "A general equilibrium entrepreneurial theory of firm formation based on risk aversion." Journal of Political economy 87 (1979): 719-748.

Klapper, Leora, Luc Laeven, and Raghuram Rajan. "Entry regulation as a barrier to entrepreneurship.” Journal of Financial Economics 82 (2006): 591-629.

Kline, Patrick, Neviana Petkova, Heidi Williams, and Owen Zidar. "Who profits from patents? rent-sharing at innovative firms.” The Quarterly Journal of Economics 134 (2019): 1343-1404.

Knight, Frank H., "Risk, uncertainty and profit.” New York: Houghton-Mifflin (1921).

Koustas, Dmitri. "Consumption insurance and multiple jobs: Evidence from rideshare drivers." Working paper (2018). 
Levine, Ross, and Yona Rubinstein. "Smart and illicit: who becomes an entrepreneur and do they earn more?" Quarterly Journal of Economics 132 (2017): 963-1018.

Levine, Ross, and Yona Rubinstein. "Selection into entrepreneurship and self-employment." NBER Working Paper No. w25350 (2018).

Lucas Jr, Robert E. "Asset prices in an exchange economy." Econometrica: Journal of the Econometric Society (1978): 1429-1445.

LeRoy, Stephen F., and Larry D. Singell Jr. "Knight on Risk and Uncertainty." Journal of Political Economy 95 (1987): 394-406.

Schumpeter, Joseph A. "The Theory of Economic Development." Cambridge, MA: Harvard University Press (1934).

Schumpeter, Joseph A. "Socialism, capitalism and democracy." Harper and Brothers (1942). 


\section{FIGURES}

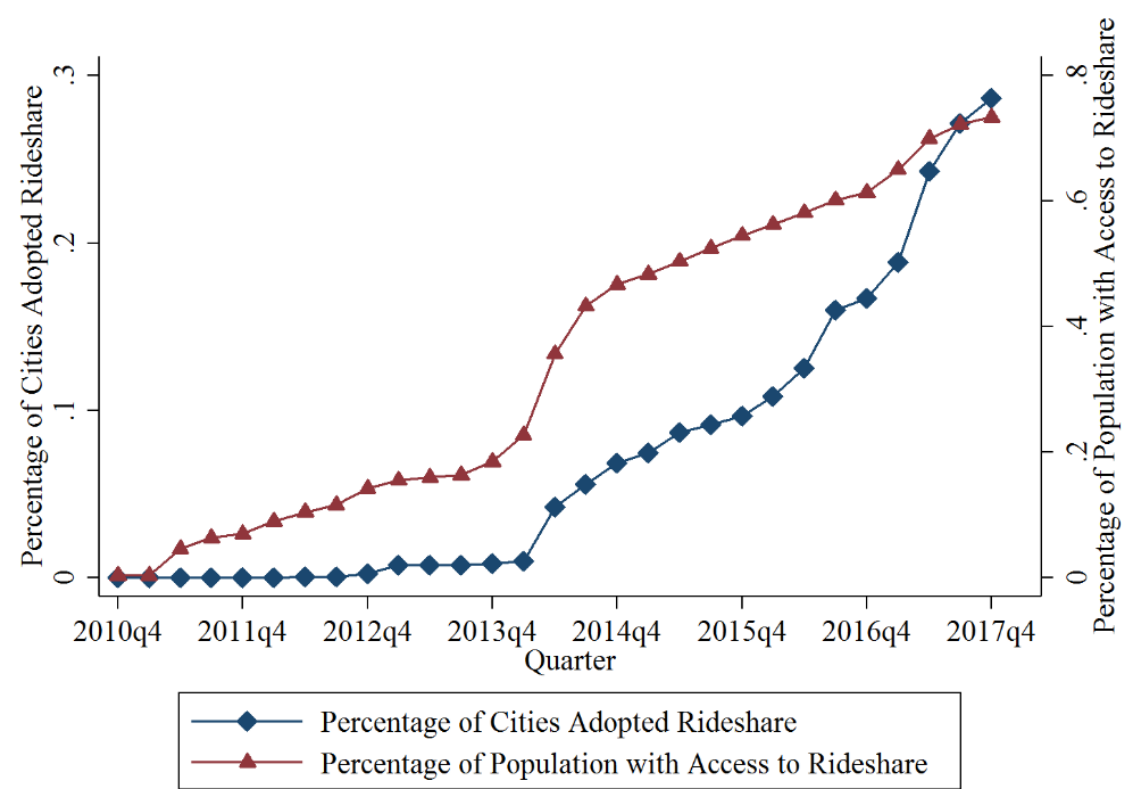

Figure 1

Ridehailing Diffusion

This figure shows the diffusion of ridehailing across the U.S. by cities and population. The sample consists of all census incorporated places in the United States. The navy (red) line graphs the percentage of cities (population) that adopted ridehailing in each quarter between the fourth quarter of 2010 and the fourth quarter of 2017. 


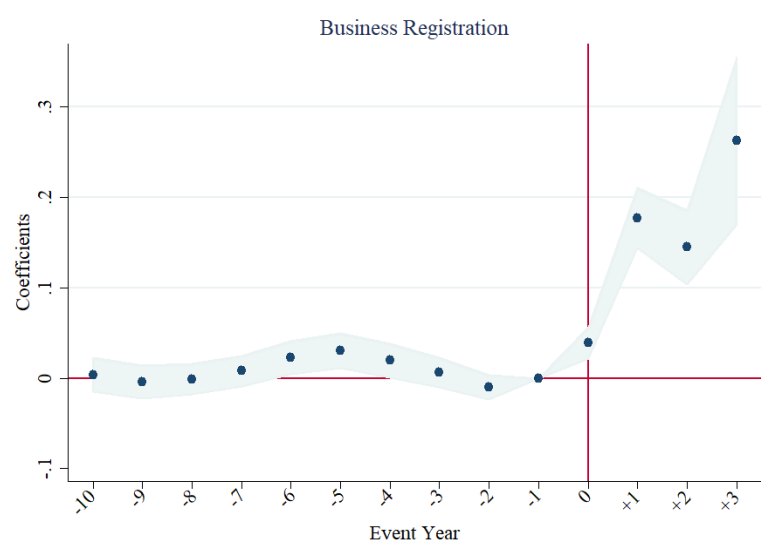

Panel A

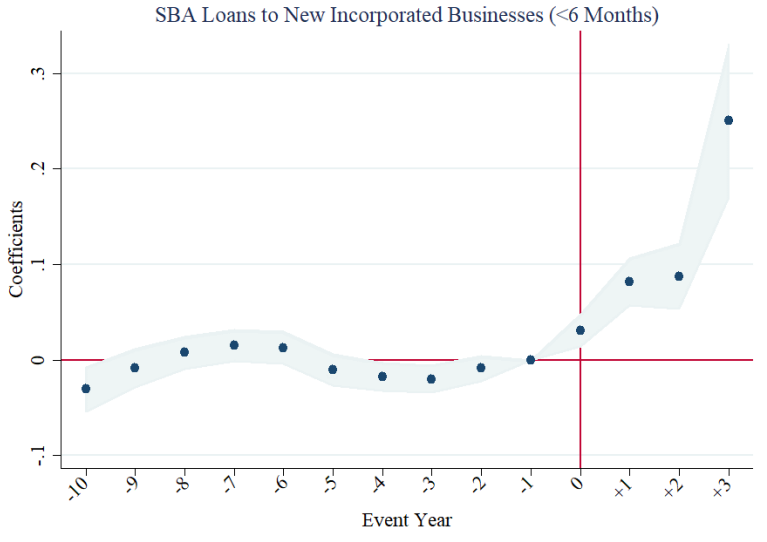

Panel B

Figure 2

Difference-in-Difference Estimators

This figure displays the regression coefficient estimates for our three main outcomes and two-tailed $95 \%$ confidence intervals based on standard errors clustered at the city level. The outcome variables in Panel A is the natural logarithm of one plus new business registrations. The outcome variable in Panel B is the natural logarithm of one plus the number of SBA loans issued to newly-registered business. To map out the pattern in the counterfactual treatment effects, we regress the outcome variables on the lag and lead indicators (bunched by four quarters) of the ridehailing entry. The sample includes all rideshare cities in years after 2005. The vertical red line indicates the quarter of entry. 


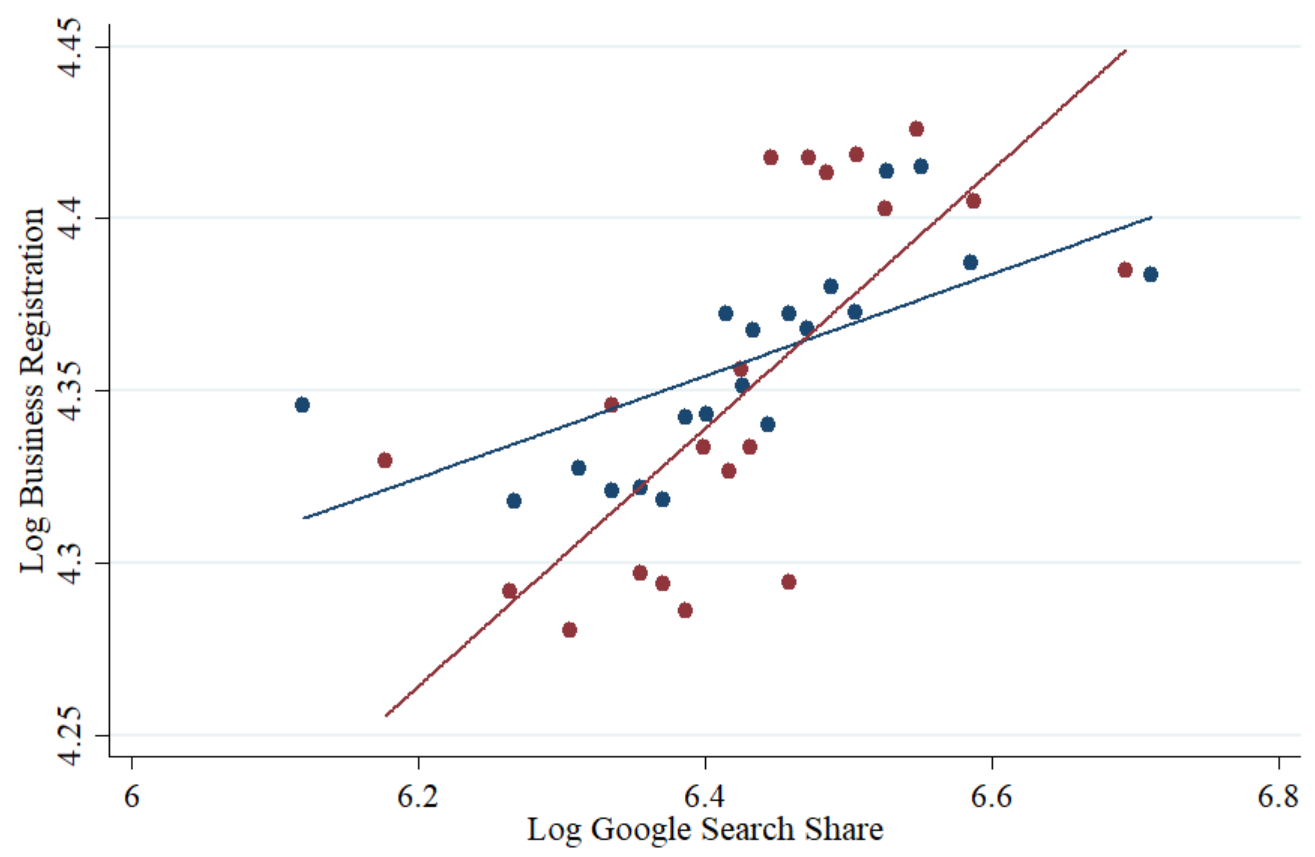

- Rideshare X Post $=0 \quad$ Rideshare X Post $=1$

Figure 3

Relation between Search Activity and New Business Registration

This figure plots the relation between new business registration and entrepreneurship-related Google search share before and after the entry of ridehailing. Blue points represent pre-ridehailing city-quarter observations. Red points represent post-ridehailing city-quarter observations. 


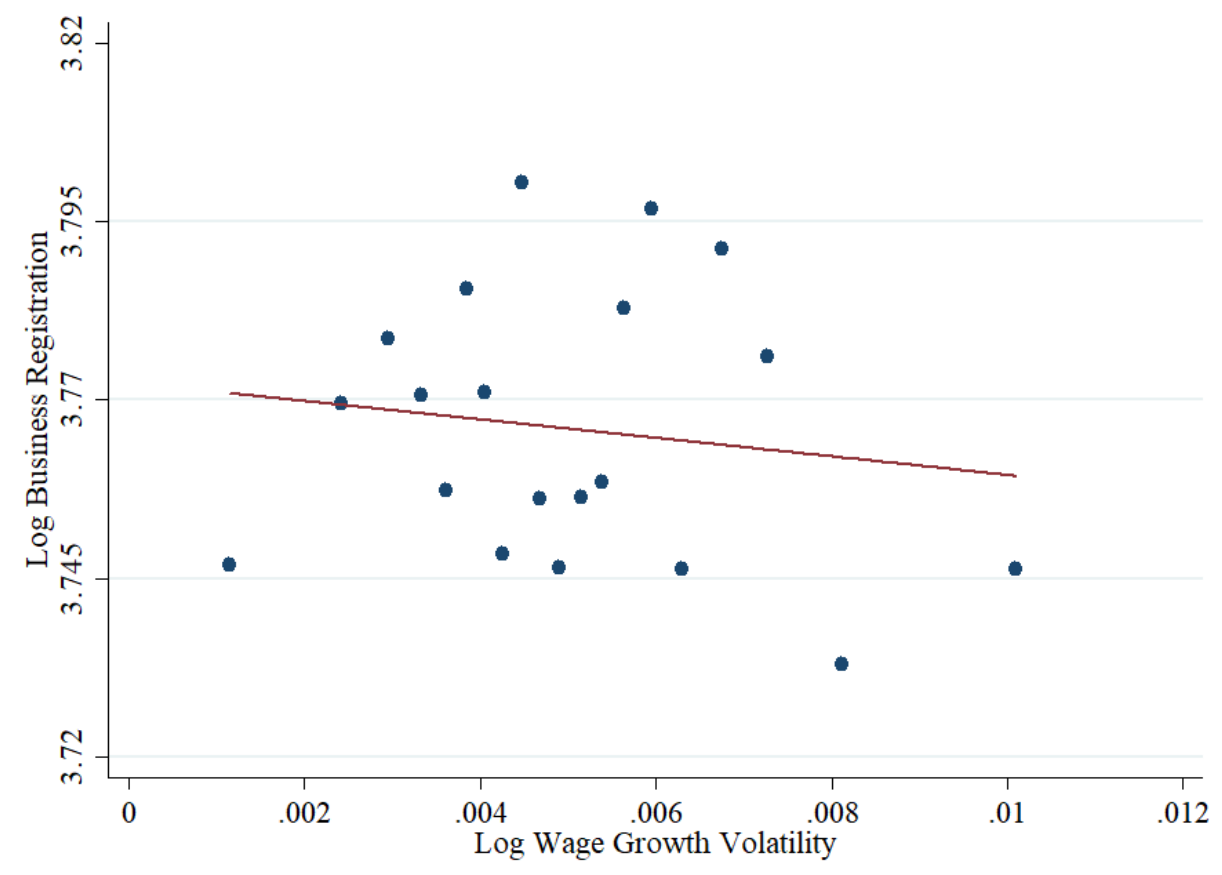

Figure 4

Relation between Wage Growth Volatility and New Business Registration

This figure plots the relation between wage growth volatility and new business registration. Wage growth volatility is the weighted sum of the variances and covariances of wage growth rate in the sectors of the economy, weighted by the employment share of each individual sector. Mathematically, it is expressed as:

$$
\sigma_{p}^{2}=\sum_{i} w_{i}^{2} \sigma_{i}^{2}+\sum_{i \neq j} \sum_{i \neq j} w_{i} w_{j} \sigma_{i j}
$$

where $w_{j}$ denotes the proportion of total employment in industry $\mathrm{j}, \sigma_{j}^{2}$ denotes the variance of wage growth rate in industry $\mathrm{j}$, and $p$ denotes city. 

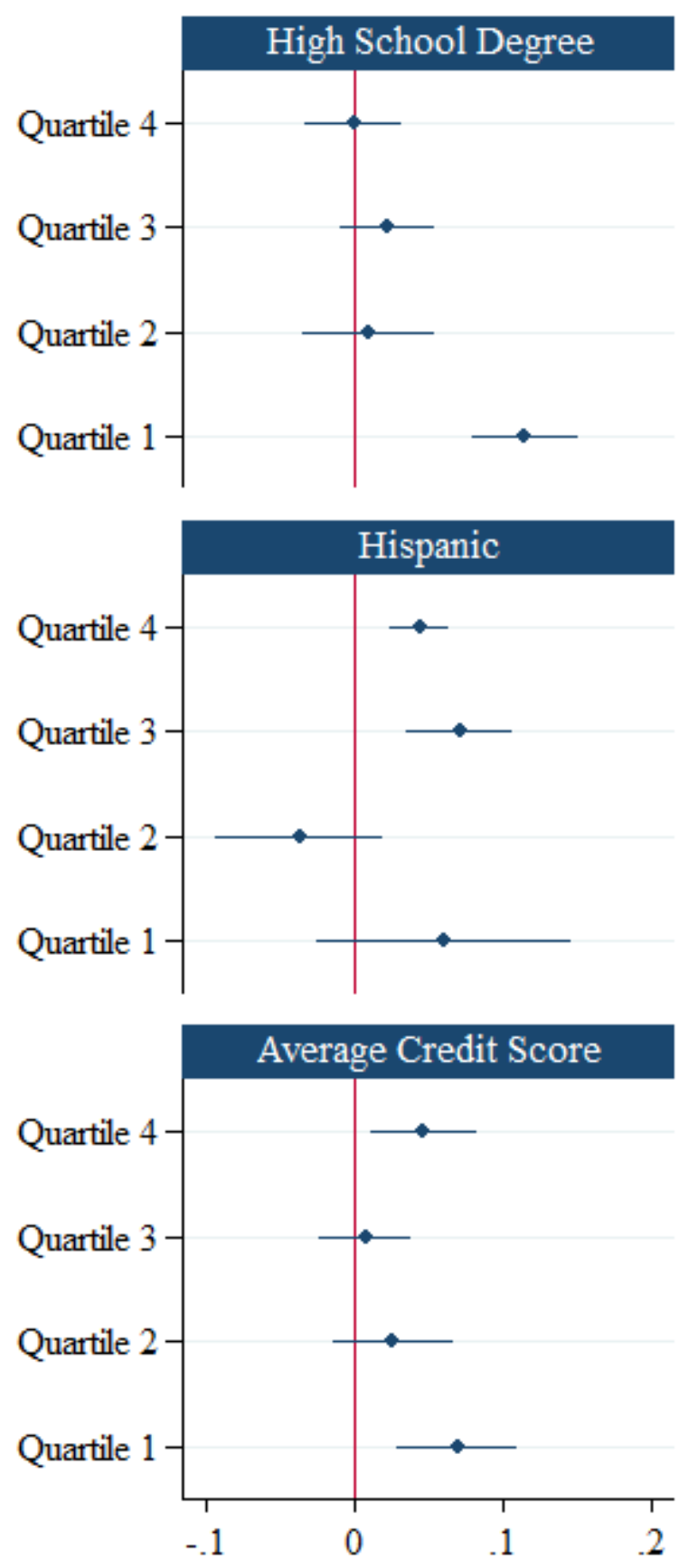

Figure 5

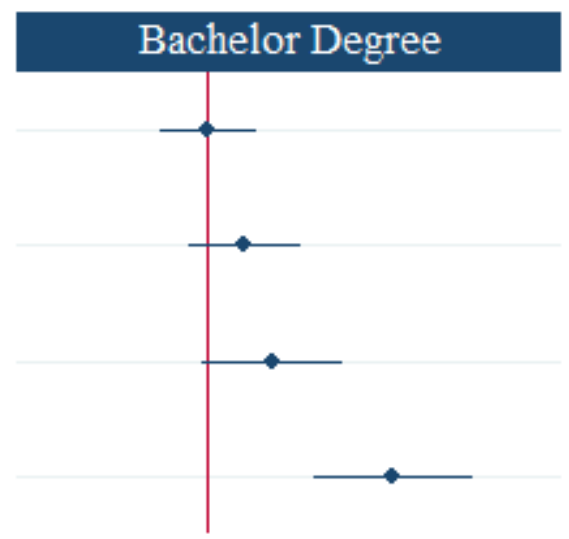

\section{Black and African American}

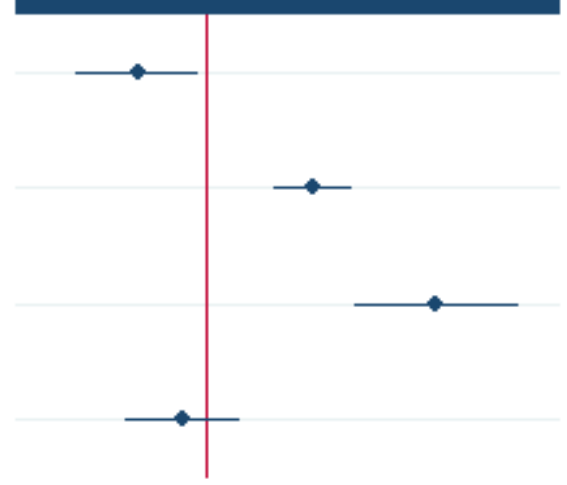

Fraction of Subprime

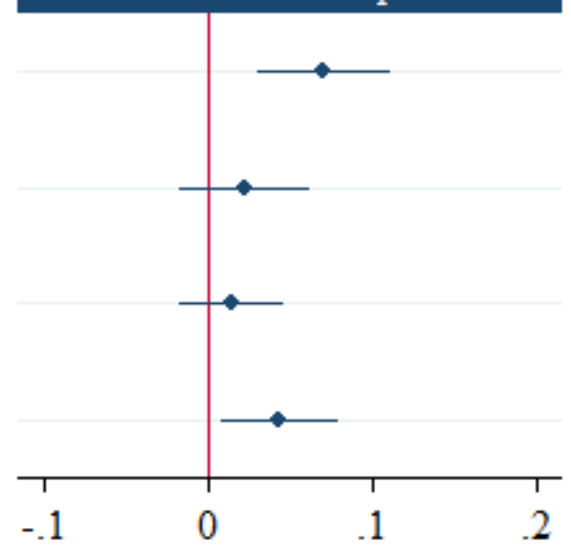

\section{Heterogeneity by City Characteristics}

This figure displays the regression coefficient estimates in Table 10 and two-tailed $95 \%$ confidence intervals based on standard errors clustered at the city level. We break out the effect of rideshare entry by the fraction of population in a city with high school degrees, the fraction of population in a city with bachelor's degrees, the fraction of Hispanic population in a city, the fraction of black and African American population, average credit score, and the fraction of subprime borrowers, i.e. borrowers with credit scores below 660. The outcome variable for all panels is the natural $\log$ of new business registrations. 


\section{TABLES}

Table 1

Summary Statistics

\begin{tabular}{lccccc}
\hline Variable & Mean & SD & P10 & Median & P90 \\
\hline & & & & & \\
Business Registration & 133.7 & 391.2 & 5.0 & 47.0 & 283.0 \\
SBA Loans to New Businesses (Count) & 0.4 & 1.7 & 0.0 & 0.0 & 1.0 \\
SBA Loans to New Businesses (Amount \$K) & 127.6 & 718.4 & 0.0 & 0.0 & 215.0 \\
Google Search Share & 713.0 & 382.2 & 443.1 & 631.7 & 1109.8 \\
Population & 54348.2 & 199878.5 & 11224.0 & 23398.0 & 93807.0 \\
Income Per Capita & 39.3 & 12.2 & 26.5 & 37.1 & 55.1 \\
Credit Score & 669.5 & 33.6 & 626.8 & 668.7 & 713.7 \\
Subprime Borrowers (\%) & 44.1 & 13.5 & 26.2 & 44.3 & 61.2 \\
Low Income (\%) & 49.1 & 12.1 & 32.4 & 49.6 & 64.4 \\
High School Degree (\%) & 85.6 & 9.3 & 74.1 & 87.4 & 95.4 \\
Bachelor's Degree (\%) & 28.6 & 15.1 & 12.9 & 24.7 & 50.6 \\
Black and African American Population (\%) & 11.9 & 12.2 & 1.1 & 7.7 & 27.3 \\
Hispanic Population (\%) & 15.8 & 16.3 & 2.2 & 9.1 & 40.9 \\
Wage Growth Volatility (\%) & 0.6 & 0.4 & 0.3 & 0.6 & 1.2 \\
Entrepreneurial Quality Index & 0.0006 & 0.0014 & 0.0002 & 0.0004 & 0.0008 \\
\hline
\end{tabular}

Notes: The sample contains 201,212 quarterly observations on 2,959 census incorporated places from 2000 to 2016. Business Registration measures the number of new business registrations in a city-quarter. SBA Loan to New Businesses (Count) measures the total number of SBA 7(a) loans issued to businesses registered within 12 months. SBA Loan to New Businesses (Amount \$K) measures the total amount of SBA 7(a) loans issued to businesses registered within 12 months. Google Search Share measures the share of google search volume for the terms such as "how to start a business". Subprime Borrowers measures the fraction of borrowers in a city-quarter that has below 660 credit score. Wage growth volatility is the weighted sum of the variances and covariances of wage growth rate in the sectors of the economy, weighted by the employment share of each individual sector. Entrepreneurial Quality Index measures average entrepreneurial quality in a given city-quarter, as defined in Guzman and Stern (2019). 
Table 2

Gig Economy and New Business Registration

\begin{tabular}{lcccc}
\hline & \multicolumn{4}{c}{ Log $(1+$ New Business Registration $)$} \\
\cline { 2 - 5 } & $>2000$ & $(2)$ & $(3)$ & $(4)$ \\
& & & & \\
& & & & \\
& & & & \\
Treat X Post & $0.0389^{* * *}$ & $0.0676^{* * *}$ & $0.0527^{* * *}$ & $0.0594^{* * * *}$ \\
& $(0.0112)$ & $(0.0121)$ & $(0.0105)$ & $(0.0108)$ \\
Log Pop & $0.7358^{* * *}$ & $0.3212^{* * *}$ & $0.7164^{* * *}$ & $0.1987^{*}$ \\
& $(0.0928)$ & $(0.1087)$ & $(0.1189)$ & $(0.1094)$ \\
Log Income Per Capita (lag) & $0.5212^{* * *}$ & $0.5094^{* * *}$ & $0.2297^{* * *}$ & 0.0262 \\
& $(0.0572)$ & $(0.0668)$ & $(0.0715)$ & $(0.0728)$ \\
Unemployment Rate (lag) & 0.0004 & $-0.0052^{* *}$ & $-0.0125^{* * *}$ & $-0.0186^{* * *}$ \\
& $(0.0018)$ & $(0.0021)$ & $(0.0021)$ & $(0.0023)$ \\
Observations & & & & \\
R-squared & 195,446 & 139,225 & 114,384 & 81,761 \\
City FE & 0.9590 & 0.9592 & 0.9665 & 0.9683 \\
Quarter FE & Yes & Yes & Yes & Yes \\
City Linear Trend & Yes & Yes & Yes & Yes \\
\hline
\end{tabular}

Notes: This table presents results from generalized difference-in-difference regressions. The dependent variable is listed at the top of the table. Treat X Post is a dummy variable that equals one if city $\mathrm{c}$ adopted at least one ridehailing service (proxy for gig economy arrival) at time t. Control variables in the regressions include the natural logarithm of population, income per capita (lagged one quarter), and unemployment rate (lagged one quarter). Standard errors, adjusted for clustering at the city level, are reported in parentheses. ***,**, and * represent statistical significance at the $1 \%, 5 \%$, and $10 \%$ levels, respectively. 
Table 3

Intensity of Gig Economy Adoption and New Business Registration

\begin{tabular}{|c|c|c|c|c|}
\hline & \multicolumn{4}{|c|}{ Log (1+New Business Registration) } \\
\hline & (1) & (2) & (3) & (4) \\
\hline & $>2000$ & $>2005$ & Treat $=1$ & $\begin{array}{l}>2005 \& \\
\text { Treat }=1\end{array}$ \\
\hline Treat X Post X Log (Ridehailing-Related Search Share) & $\begin{array}{c}0.0772 * * * \\
(0.0109)\end{array}$ & $\begin{array}{c}0.0765 * * * \\
(0.0111)\end{array}$ & $\begin{array}{c}0.0660 * * * \\
(0.0111)\end{array}$ & $\begin{array}{c}0.0664 * * * \\
(0.0113)\end{array}$ \\
\hline Log Pop & $\begin{array}{c}0.4114 * * * \\
(0.0981)\end{array}$ & $\begin{array}{c}0.2942 * * * \\
(0.1087)\end{array}$ & $\begin{array}{c}0.3274 * * * \\
(0.1047)\end{array}$ & $\begin{array}{c}0.1712 \\
(0.1097)\end{array}$ \\
\hline Log Income Per Capita (lag) & $\begin{array}{c}0.4415 * * * \\
(0.0630)\end{array}$ & $\begin{array}{c}0.4587 * * * \\
(0.0672)\end{array}$ & $\begin{array}{l}-0.0303 \\
(0.0702)\end{array}$ & $\begin{array}{l}-0.0262 \\
(0.0723)\end{array}$ \\
\hline Unemployment Rate (lag) & $\begin{array}{l}-0.0000 \\
(0.0021)\end{array}$ & $\begin{array}{l}-0.0034 \\
(0.0021)\end{array}$ & $\begin{array}{c}-0.0135 * * * \\
(0.0023)\end{array}$ & $\begin{array}{c}-0.0164 * * * \\
(0.0023)\end{array}$ \\
\hline Observations & 151,061 & 139,225 & 88,629 & 81,761 \\
\hline R-squared & 0.9598 & 0.9593 & 0.9685 & 0.9684 \\
\hline Lower Order Interaction Terms & Yes & Yes & Yes & Yes \\
\hline City FE & Yes & Yes & Yes & Yes \\
\hline Quarter FE & Yes & Yes & Yes & Yes \\
\hline City Linear Trend & Yes & Yes & Yes & Yes \\
\hline
\end{tabular}

Notes: This table shows how the effect of ridehailing on new business registrations vary with the intensity of ridehailing service. The dependent variable is listed at the top of the table. Log Ridehail Google Search Share is the natural logarithm of Google search share for the terms "Uber," "Lyft," and "rideshare." Treat X Post is a dummy variable that equals one if city c adopted at least one ridehailing service (proxy for gig economy arrival) at time t. Control variables in the regressions include the natural logarithm of population, income per capita (lagged one quarter), and unemployment rate (lagged one quarter). Standard errors, adjusted for clustering at the city level, are reported in parentheses. $* * *, * *$, and $*$ represent statistical significance at the $1 \%, 5 \%$, and $10 \%$ levels, respectively. 
Table 4

Modeling Ridehail Adoption: Cox Proportional Hazard Model

\begin{tabular}{|c|c|c|c|c|}
\hline & $\begin{array}{c}\text { (1) } \\
\text { All Cities }\end{array}$ & $\begin{array}{c}(2) \\
\text { Rideshare } \\
\text { Cities }\end{array}$ & $\begin{array}{c}\text { (3) } \\
\text { All Cities }\end{array}$ & $\begin{array}{c}(4) \\
\text { Rideshare } \\
\text { Cities } \\
\end{array}$ \\
\hline Annual \% Change in Business Registration & $\begin{array}{c}0.9994 \\
(0.0059)\end{array}$ & $\begin{array}{c}0.9969 \\
(0.0057)\end{array}$ & & \\
\hline Annual \% Change in Business Registration Per Capita & & & $\begin{array}{c}0.9994 \\
(0.0059)\end{array}$ & $\begin{array}{c}0.9970 \\
(0.0057)\end{array}$ \\
\hline Annual \% Change in Pop & $\begin{array}{c}1.2200 * * * \\
(0.0481)\end{array}$ & $\begin{array}{l}0.9087^{*} \\
(0.0509)\end{array}$ & $\begin{array}{c}1.2199 * * * \\
(0.0481)\end{array}$ & $\begin{array}{l}0.9086^{*} \\
(0.0509)\end{array}$ \\
\hline Annual \% Change in Income & $\begin{array}{c}1.3545 * * * \\
(0.0543)\end{array}$ & $\begin{array}{c}1.2515 * * * \\
(0.0611)\end{array}$ & $\begin{array}{c}1.3545 * * * \\
(0.0543)\end{array}$ & $\begin{array}{c}1.2515 * * * \\
(0.0611)\end{array}$ \\
\hline Annual \% Change in Unemployment Rate & $\begin{array}{c}0.8844 \\
(0.0708)\end{array}$ & $\begin{array}{c}0.8089 * * \\
(0.0783)\end{array}$ & $\begin{array}{c}0.8844 \\
(0.0708)\end{array}$ & $\begin{array}{c}0.8089 * * \\
(0.0783)\end{array}$ \\
\hline Observations & 41,664 & 23,950 & 41,664 & 23,950 \\
\hline
\end{tabular}

Notes: This table presents results from proportional cox hazard model estimations. The reported coefficient estimates are hazard ratios. We collapse observations at the city-year level to calculate annual percentage changes in business registration, business registration per capita, population, income, and unemployment rate. All variables are standardized to facilitate comparison between estimated hazard ratios. In Columns (1) and (3), we include all cities in our sample. In Columns (2) and (4), we limit the analysis to cities that adopted rideshare during our sample period. Standard errors, adjusted for clustering at the city level, are reported in parentheses. $* * *, * *$, and $*$ represent statistical significance at the $1 \%, 5 \%$, and $10 \%$ levels, respectively. 
Table 5

Gig Economy and Small Business Loans to Newly Registered Businesses

Panel A: Firms Registered Within 6 Months

\begin{tabular}{|c|c|c|c|c|}
\hline & \multicolumn{4}{|c|}{ Log SBA Loans to Newly Registered Firms $(<6 \mathrm{M})$} \\
\hline & (1) & $(2)$ & (3) & (4) \\
\hline & $>2000$ & $>2005$ & Treat $=1$ & $>2005 \&$ Treat $=1$ \\
\hline \multirow[t]{2}{*}{ Treat X Post } & $0.0555 * * *$ & $0.0780 * * *$ & $0.0348 * * *$ & $0.0509 * * *$ \\
\hline & $(0.0065)$ & $(0.0078)$ & $(0.0073)$ & $(0.0084)$ \\
\hline \multirow[t]{2}{*}{ Log Pop } & $0.1246 * * *$ & $0.3247 * * *$ & $0.1200 * * *$ & $0.4040 * * *$ \\
\hline & $(0.0372)$ & $(0.0566)$ & $(0.0436)$ & $(0.0749)$ \\
\hline \multirow[t]{2}{*}{ Log Income Per Capita (lag) } & $0.0888 * * *$ & $0.2792 * * *$ & $0.0899 *$ & $0.3088 * * *$ \\
\hline & $(0.0300)$ & $(0.0372)$ & $(0.0497)$ & $(0.0635)$ \\
\hline \multirow{2}{*}{ Unemployment Rate (lag) } & $-0.0019 *$ & $-0.0022 *$ & $-0.0029 *$ & $-0.0031^{*}$ \\
\hline & $(0.0010)$ & $(0.0012)$ & $(0.0015)$ & $(0.0018)$ \\
\hline Observations & 198,238 & 142,017 & 115,024 & 82,401 \\
\hline R-squared & 0.5179 & 0.5467 & 0.5592 & 0.5837 \\
\hline City FE & Yes & Yes & Yes & Yes \\
\hline Quarter FE & Yes & Yes & Yes & Yes \\
\hline City Linear Trend & Yes & Yes & Yes & Yes \\
\hline
\end{tabular}

$\underline{\text { Panel B: Firms Registered Within } 12 \text { Months }}$

\begin{tabular}{|c|c|c|c|c|}
\hline & \multicolumn{4}{|c|}{ Log SBA Loans to Newly Registered Firms $(<12 \mathrm{M})$} \\
\hline & (1) & (2) & (3) & (4) \\
\hline & $>2000$ & $>2005$ & Treat $=1$ & $>2005 \&$ Treat $=1$ \\
\hline \multirow[t]{2}{*}{ Treat X Post } & $0.0609 * * *$ & $0.0897 * * *$ & $0.0385 * * *$ & $0.0588 * * *$ \\
\hline & $(0.0071)$ & $(0.0088)$ & $(0.0079)$ & $(0.0092)$ \\
\hline \multirow[t]{2}{*}{ Log Pop } & $0.1408 * * *$ & $0.3961 * * *$ & $0.1359 * * *$ & $0.4682 * * *$ \\
\hline & $(0.0438)$ & $(0.0724)$ & $(0.0522)$ & $(0.0953)$ \\
\hline \multirow[t]{2}{*}{ Log Income Per Capita (lag) } & $0.1018 * * *$ & $0.3541 * * *$ & $0.1070 *$ & $0.3789 * * *$ \\
\hline & $(0.0349)$ & $(0.0453)$ & $(0.0579)$ & $(0.0777)$ \\
\hline \multirow[t]{2}{*}{ Unemployment Rate (lag) } & $-0.0028 * *$ & $-0.0042 * * *$ & $-0.0043 * *$ & $-0.0054 * *$ \\
\hline & $(0.0011)$ & $(0.0014)$ & $(0.0018)$ & $(0.0021)$ \\
\hline Observations & 198,238 & 142,017 & 115,024 & 82,401 \\
\hline R-squared & 0.5703 & 0.6009 & 0.6086 & 0.6346 \\
\hline City FE & Yes & Yes & Yes & Yes \\
\hline Quarter FE & Yes & Yes & Yes & Yes \\
\hline City Linear Trend & Yes & Yes & Yes & Yes \\
\hline
\end{tabular}

Notes: This table presents results from generalized difference-in-difference regressions. The dependent variable in Panel A is the natural logarithm of the number of SBA loans to firms that are incorporated in less than 6 months. The dependent variable in Panel B is the natural logarithm of the number of SBA loans to firms that are incorporated in less than 12 months. Treat X Post is a dummy variable that equals one if city c adopted at least one ridehailing service at time t. Control variables in the regressions include the natural logarithm of population, income per capita (lagged one quarter), and unemployment rate (lagged one quarter). Standard errors, adjusted for clustering at the city level, are reported in parentheses. $* * *, * *$, and $*$ represent statistical significance at the $1 \%, 5 \%$, and $10 \%$ levels, respectively. 
Table 6

Gig Economy and Entrepreneurial Interest (Search Share)

\begin{tabular}{lcccc}
\hline & $(1)$ & $(2)$ & $(3)$ & $(4)$ \\
& $>2000$ & $>2005$ & Treat $=1$ & $\begin{array}{c}>2005 \& \\
\text { Treat }=1\end{array}$ \\
\hline Treat X Post & & & & \\
& $0.1136^{* * *}$ & $0.0677^{* * *}$ & $0.1237^{* * *}$ & $0.0619^{* * *}$ \\
& $(0.0121)$ & $(0.0094)$ & $(0.0148)$ & $(0.0108)$ \\
Observations & & & & \\
R-squared & 153,853 & 142,017 & 89,269 & 82,401 \\
Controls & 0.6140 & 0.6663 & 0.5875 & 0.6473 \\
City FE & Yes & Yes & Yes & Yes \\
Quarter FE & Yes & Yes & Yes & Yes \\
City Linear Trend & Yes & Yes & Yes & Yes \\
\hline
\end{tabular}

Notes: This table presents the effect of gig economy arrival on entrepreneurial intent, measured using google search share for entrepreneurship-related phrases, such as "start a business", "how to incorporate", and "become an entrepreneur". The outcome variable is the natural log of one plus google search share. Control variables in the regressions include the natural logarithm of population, income per capita (lagged one quarter), and unemployment rate (lagged one quarter). Standard errors, clustered at city level, are reported in parentheses. $* * *, * *$, and $*$ represent statistical significance at the $1 \%, 5 \%$, and $10 \%$ levels, respectively. 
Table 7

Mechanisms for Growth in Entrepreneurial Entry

Panel A: Income Log (1+New Business Registration)

\begin{tabular}{|c|c|c|c|c|}
\hline & \multicolumn{4}{|c|}{ Log (1+New Business Registration) } \\
\hline & $(1)$ & $(2)$ & (3) & (4) \\
\hline & $>2000$ & $>2005$ & Treat $=1$ & $>2005 \&$ Treat $=1$ \\
\hline \multirow[t]{2}{*}{ Treat X Post X Personal Income } & $-0.0207^{* *}$ & $-0.0185^{* *}$ & $-0.0185^{* *}$ & $-0.0143^{*}$ \\
\hline & $(0.0083)$ & $(0.0084)$ & $(0.0082)$ & $(0.0083)$ \\
\hline \multirow[t]{2}{*}{ Treat X Post } & $0.0431 * * *$ & $0.0710^{* * *}$ & $0.0566^{* * *}$ & $0.0622 * * *$ \\
\hline & $(0.0120)$ & $(0.0129)$ & $(0.0113)$ & $(0.0117)$ \\
\hline \multirow[t]{2}{*}{ Log Pop } & $0.7362 * * *$ & $0.3219 * * *$ & $0.7165^{* * *}$ & $0.1982 *$ \\
\hline & $(0.0928)$ & $(0.1088)$ & $(0.1189)$ & $(0.1095)$ \\
\hline \multirow[t]{2}{*}{ Log Income Per Capita (lag) } & $0.5263 * * *$ & $0.5177 * * *$ & $0.2380 * * *$ & 0.0377 \\
\hline & $(0.0572)$ & $(0.0668)$ & $(0.0715)$ & $(0.0725)$ \\
\hline \multirow[t]{2}{*}{ Unemployment Rate (lag) } & 0.0004 & $-0.0052^{* *}$ & $-0.0125 * * *$ & $-0.0186^{* * *}$ \\
\hline & $(0.0018)$ & $(0.0021)$ & $(0.0021)$ & $(0.0023)$ \\
\hline Observations & 195,379 & 139,177 & 114,384 & 81,761 \\
\hline R-squared & 0.9590 & 0.9592 & 0.9666 & 0.9683 \\
\hline Controls & Yes & Yes & Yes & Yes \\
\hline City FE & Yes & Yes & Yes & Yes \\
\hline Quarter FE & Yes & Yes & Yes & Yes \\
\hline City Linear Trend & Yes & Yes & Yes & Yes \\
\hline
\end{tabular}

Panel B: Wage Growth Volatility

\begin{tabular}{|c|c|c|c|c|}
\hline & \multicolumn{4}{|c|}{ Log (1+New Business Registration) } \\
\hline & (1) & (2) & (3) & (4) \\
\hline & $>2000$ & $>2005$ & Treat $=1$ & $>2005 \&$ Treat $=1$ \\
\hline \multirow[t]{2}{*}{ Treat X Post X Wage Growth Volatility } & $0.0293 * * *$ & $0.0163 * *$ & $0.0268 * * *$ & $0.0108^{*}$ \\
\hline & $(0.0067)$ & $(0.0065)$ & $(0.0067)$ & $(0.0064)$ \\
\hline \multirow[t]{2}{*}{ Treat X Post } & $0.0339 * * *$ & $0.0652 * * *$ & $0.0484 * * *$ & $0.0580 * * *$ \\
\hline & $(0.0115)$ & $(0.0125)$ & $(0.0108)$ & $(0.0111)$ \\
\hline \multirow[t]{2}{*}{ Average Wage Growth } & $-0.0610^{* * *}$ & $-0.0389^{*}$ & -0.0242 & -0.0173 \\
\hline & $(0.0192)$ & $(0.0200)$ & $(0.0242)$ & $(0.0243)$ \\
\hline \multirow[t]{2}{*}{ Log Pop } & $0.7258 * * *$ & $0.3151 * * *$ & $0.7032 * * *$ & $0.1932 *$ \\
\hline & $(0.0925)$ & $(0.1085)$ & $(0.1185)$ & $(0.1092)$ \\
\hline \multirow[t]{2}{*}{ Log Income Per Capita (lag) } & $0.5314 * * *$ & $0.5166^{* * *}$ & $0.2464 * * *$ & 0.0352 \\
\hline & $(0.0574)$ & $(0.0670)$ & $(0.0721)$ & $(0.0735)$ \\
\hline \multirow[t]{2}{*}{ Unemployment Rate (lag) } & 0.0006 & $-0.0050 * *$ & $-0.0122 * * *$ & $-0.0184 * * *$ \\
\hline & $(0.0019)$ & $(0.0021)$ & $(0.0021)$ & $(0.0023)$ \\
\hline Observations & 195,446 & 139,225 & 114,384 & 81,761 \\
\hline R-squared & 0.9590 & 0.9592 & 0.9666 & 0.9683 \\
\hline Controls & Yes & Yes & Yes & Yes \\
\hline City FE & Yes & Yes & Yes & Yes \\
\hline Quarter FE & Yes & Yes & Yes & Yes \\
\hline City Linear Trend & Yes & Yes & Yes & Yes \\
\hline \multicolumn{5}{|c|}{$\begin{array}{l}\text { Notes: This table presents heterogeneous effects of ridehailing on entrepreneurship by city average personal income and wage growth volatility } \\
\text { The dependent variable is the natural log of new business registrations. Personal Income is standardized average personal income in a county using } \\
\text { the credit bureau data. Wage growth volatility is the standardized weighted sum of the variances and covariances of wage growth in the sectors of } \\
\text { the economy, weighted by the employment share of each individual sector as measured up until the quarter before RH entry. Both Personal Income } \\
\text { and Wage growth volatility are standardized to have a mean of zero and a standard deviation of } 1 \text {. Because this measure in not at the annual level } \\
\text { but measured once per city as of } 2010 \text {, the lower order term is absorbed in the city FE. Treat X Post is a dummy variable that equals one if city c } \\
\text { adopted at least one ridehailing service at time t. Average Wage Growth is the quarterly weighted average wage growth in all industries in a city } \\
\text { weighted by the employment share of each industry. Standard errors, adjusted for clustering at the city level, are reported in parentheses. } * * *, * * \\
\text { and } * \text { represent statistical significance at the } 1 \%, 5 \% \text {, and } 10 \% \text { levels, respectively. }\end{array}$} \\
\hline
\end{tabular}


Table 8

Gig Economy and the Nature of Entrepreneurial Activity

Panel A: Entrepreneurship Quality

\begin{tabular}{|c|c|c|c|c|}
\hline & \multicolumn{4}{|c|}{ Entrepreneurship Quality Index } \\
\hline & (1) & (2) & (3) & (4) \\
\hline & $>2000$ & $>2005$ & Treat $=1$ & $>2005 \&$ Treat $=1$ \\
\hline \multirow[t]{2}{*}{ Treat X Post } & 0.000004 & -0.000015 & 0.000012 & 0.000006 \\
\hline & $(0.000021)$ & $(0.000020)$ & $(0.000021)$ & $(0.000019)$ \\
\hline \multirow[t]{2}{*}{ Log Pop } & 0.000113 & 0.000000 & 0.000025 & -0.000084 \\
\hline & $(0.000095)$ & $(0.000123)$ & $(0.000090)$ & $(0.000116)$ \\
\hline \multirow[t]{2}{*}{ Log Income Per Capita (lag) } & 0.000135 & 0.000156 & 0.000144 & 0.000193 \\
\hline & $(0.000119)$ & $(0.000143)$ & $(0.000172)$ & $(0.000201)$ \\
\hline \multirow[t]{2}{*}{ Unemployment Rate (lag) } & -0.000000 & 0.000002 & -0.000002 & -0.000000 \\
\hline & $(0.000004)$ & $(0.000005)$ & $(0.000004)$ & $(0.000006)$ \\
\hline Observations & 188,117 & 134,317 & 113,201 & 81,043 \\
\hline R-squared & 0.2849 & 0.3272 & 0.2685 & 0.2891 \\
\hline City FE & Yes & Yes & Yes & Yes \\
\hline Quarter FE & Yes & Yes & Yes & Yes \\
\hline City Linear Trend & Yes & Yes & Yes & Yes \\
\hline \multicolumn{5}{|c|}{ Panel B: Entrepreneurship Concentration } \\
\hline & \multicolumn{4}{|c|}{ Business Registration Zip HHI } \\
\hline & (1) & (2) & (3) & (4) \\
\hline & $>2000$ & $>2005$ & Treat $=1$ & $>2005 \&$ Treat $=1$ \\
\hline \multirow[t]{2}{*}{ Treat X Post } & $0.0036^{* *}$ & -0.0009 & $0.0032 *$ & 0.0008 \\
\hline & $(0.0018)$ & $(0.0020)$ & $(0.0018)$ & $(0.0019)$ \\
\hline \multirow[t]{2}{*}{ Log Pop } & $-0.0513 * * *$ & -0.0285 & $-0.0421 * *$ & $-0.0413 * *$ \\
\hline & $(0.0138)$ & $(0.0191)$ & $(0.0180)$ & $(0.0197)$ \\
\hline \multirow[t]{2}{*}{ Log Income Per Capita (lag) } & $-0.0226 * *$ & -0.0077 & -0.0025 & 0.0017 \\
\hline & $(0.0110)$ & $(0.0120)$ & $(0.0110)$ & $(0.0120)$ \\
\hline \multirow[t]{2}{*}{ Unemployment Rate (lag) } & $0.0017 * * *$ & $0.0013^{* *}$ & 0.0001 & 0.0001 \\
\hline & $(0.0005)$ & $(0.0005)$ & $(0.0005)$ & $(0.0005)$ \\
\hline Observations & 195,446 & 139,225 & 114,384 & 81,761 \\
\hline R-squared & 0.8675 & 0.8805 & 0.9328 & 0.9441 \\
\hline City FE & Yes & Yes & Yes & Yes \\
\hline Quarter FE & Yes & Yes & Yes & Yes \\
\hline City Linear Trend & Yes & Yes & Yes & Yes \\
\hline \multicolumn{5}{|c|}{$\begin{array}{l}\text { Notes: This table presents results from generalized difference-in-difference regressions. The dependent variable in Panel A is th } \\
\text { average entrepreneurial quality index defined in Guzman and Stern (2019). The dependent variable in Panel B measures th } \\
\text { concentration of new business registration in a city-quarter, measured using an HHI index that equals to the sum of the zip share } \\
\text { of business registration in a city squared. Treat X Post is a dummy variable that equals one if city c adopted at least one ridehailin } \\
\text { service at time t. Control variables in the regressions include the natural logarithm of population, income per capita (lagged on } \\
\text { quarter), and unemployment rate (lagged one quarter). Standard errors, adjusted for clustering at the city level, are reported } \\
\text { parentheses. } * * *, * * \text {, and } * \text { represent statistical significance at the } 1 \%, 5 \% \text {, and } 10 \% \text { levels, respectively. }\end{array}$} \\
\hline
\end{tabular}


Table 9

Is the Increase in Entrepreneurship Due to City Growth?

\begin{tabular}{lcccc}
\hline & \multicolumn{4}{c}{ Log Average Weekly Wage } \\
\cline { 2 - 5 } & $>2000$ & $(2)$ & $(3)$ & $(4)$ \\
& & $>2005$ & Treat $=1$ & $>2005$ \& Treat $=1$ \\
\hline \multirow{3}{*}{ Treat X Post } & $-0.0093^{* * *}$ & $-0.0045^{* * *}$ & $-0.0079^{* * *}$ & $-0.0032^{* * *}$ \\
& $(0.0009)$ & $(0.0009)$ & $(0.0011)$ & $(0.0009)$ \\
Log Pop & $0.0262^{* * *}$ & $0.0576^{* * *}$ & $0.0250^{* *}$ & $0.0646^{* * *}$ \\
& $(0.0095)$ & $(0.0132)$ & $(0.0123)$ & $(0.0157)$ \\
Log Income Per Capita (lag) & $0.2597^{* * *}$ & $0.2202^{* * *}$ & $0.2603^{* * *}$ & $0.1865^{* * *}$ \\
& $(0.0140)$ & $(0.0131)$ & $(0.0144)$ & $(0.0114)$ \\
Unemployment Rate (lag) & $-0.0033^{* * *}$ & $-0.0029^{* * *}$ & $-0.0022^{* * *}$ & $-0.0021^{* * *}$ \\
& $(0.0002)$ & $(0.0002)$ & $(0.0003)$ & $(0.0003)$ \\
& & & & \\
Observations & 198,238 & 142,017 & 115,024 & 82,401 \\
R-squared & 0.9818 & 0.9793 & 0.9813 & 0.9785 \\
City FE & Yes & Yes & Yes & Yes \\
Quarter FE & Yes & Yes & Yes & Yes \\
City Linear Trend & Yes & Yes & Yes & Yes \\
\hline
\end{tabular}

Notes: This table presents results from generalized difference-in-difference regressions. The dependent variable is the natural logarithm of average weekly wage in a city in a given quarter. Treat $X$ Post is a dummy variable that equals one if city $\mathrm{c}$ adopted at least one ridehailing service at time $t$. Control variables in the regressions include the natural logarithm of population, income per capita (lagged one quarter), and unemployment rate (lagged one quarter). Standard errors, adjusted for clustering at the city level, are reported in parentheses. $* * *, * *$, and $*$ represent statistical significance at the $1 \%, 5 \%$, and $10 \%$ levels, respectively. 
Table 10

Who are the new entrepreneurs?

\begin{tabular}{|c|c|c|c|c|c|c|}
\hline & \multicolumn{2}{|c|}{ Education } & \multicolumn{2}{|c|}{ Race } & \multicolumn{2}{|c|}{ Credit Score } \\
\hline & (1) & (2) & (3) & (4) & (5) & (6) \\
\hline & High School & Bachelor & Hispanic & $\begin{array}{c}\text { Black and } \\
\text { African } \\
\text { American }\end{array}$ & Level & $\begin{array}{l}\text { Fraction of } \\
\text { Subprime }\end{array}$ \\
\hline Treat X Post X Q1 & $\begin{array}{c}0.1148 * * * \\
(0.0185)\end{array}$ & $\begin{array}{c}0.1131 * * * \\
(0.0246)\end{array}$ & $\begin{array}{c}0.0604 \\
(0.0434)\end{array}$ & $\begin{array}{l}-0.0139 \\
(0.0179)\end{array}$ & $\begin{array}{c}0.0690 * * * \\
(0.0206)\end{array}$ & $\begin{array}{c}0.0435 * * \\
(0.0178)\end{array}$ \\
\hline Treat X Post X Q2 & $\begin{array}{c}0.0100 \\
(0.0227)\end{array}$ & $\begin{array}{l}0.0399^{*} \\
(0.0216)\end{array}$ & $\begin{array}{l}-0.0371 \\
(0.0290)\end{array}$ & $\begin{array}{c}0.1398 * * * \\
(0.0255)\end{array}$ & $\begin{array}{c}0.0262 \\
(0.0204)\end{array}$ & $\begin{array}{c}0.0147 \\
(0.0162)\end{array}$ \\
\hline Treat X Post X Q3 & $\begin{array}{c}0.0218 \\
(0.0162)\end{array}$ & $\begin{array}{c}0.0224 \\
(0.0174)\end{array}$ & $\begin{array}{c}0.0707 * * * \\
(0.0185)\end{array}$ & $\begin{array}{c}0.0651 * * * \\
(0.0124)\end{array}$ & $\begin{array}{c}0.0074 \\
(0.0159)\end{array}$ & $\begin{array}{c}0.0223 \\
(0.0203)\end{array}$ \\
\hline Treat X Post X Q4 & $\begin{array}{c}0.0000 \\
(0.0165)\end{array}$ & $\begin{array}{c}0.0005 \\
(0.0149)\end{array}$ & $\begin{array}{c}0.0441 * * * \\
(0.0102)\end{array}$ & $\begin{array}{c}-0.0419 * * \\
(0.0193)\end{array}$ & $\begin{array}{r}0.0465 * * * \\
(0.0180)\end{array}$ & $\begin{array}{c}0.0700^{* * *} * \\
(0.0206)\end{array}$ \\
\hline Observations & 195,446 & 195,446 & 195,446 & 195,446 & 195,379 & 195,379 \\
\hline R-squared & 0.9590 & 0.9590 & 0.9590 & 0.9591 & 0.9590 & 0.9590 \\
\hline Controls & Yes & Yes & Yes & Yes & Yes & Yes \\
\hline City FE & Yes & Yes & Yes & Yes & Yes & Yes \\
\hline Quarter FE & Yes & Yes & Yes & Yes & Yes & Yes \\
\hline City Linear Trend & Yes & Yes & Yes & Yes & Yes & Yes \\
\hline
\end{tabular}

Notes: This table presents heterogeneous effects of ridehailing on entrepreneurship by city characteristics. The dependent variable is the natural log of new business registrations. Column (1) breaks out the effect by the fraction of population in a city with high school degrees, column (2) by the fraction of population in a city with bachelor's degrees, column (3) by the fraction of Hispanic population in a city, column (4) by the fraction of black and African American population, column (5) by average credit score, and column (6) by the fraction of subprime borrowers, i.e. borrowers with credit scores below 660. Treat X Post is a dummy variable that equals one if city c adopted at least one ridehailing service at time t. $Q 1, Q 2, Q 3$, and $Q 4$ are indicator variables that take a value of one if a city's characteristics is in the respective quartile of distributions. Control variables in the regressions include the natural logarithm of population, income per capita (lagged one quarter), and unemployment rate (lagged one quarter). Standard errors, adjusted for clustering at the city level, are reported in parentheses. $* * *, * *$, and $*$ represent statistical significance at the $1 \%, 5 \%$, and $10 \%$ levels, respectively. 